\title{
Implantable amyloid hydrogels for promoting stem cell differentiation to neurons
}

\author{
Subhadeep Das ${ }^{1,2,3}$, Kun Zhou ${ }^{3}$, Dhiman Ghosh ${ }^{2}$, Narendra N Jha ${ }^{2}$, Pradeep K Singh ${ }^{2}$, Reeba S Jacob ${ }^{2}$, \\ Claude C Bernard ${ }^{4}$, David I Finkelstein ${ }^{5}$, John S Forsythe ${ }^{3}$ and Samir K Maji ${ }^{2}$
}

We report a new class of amyloid-inspired peptide hydrogels that was designed and based on $\alpha$-synuclein protein for which hydrogel formation is triggered by various stimuli, such as heating/cooling or changes in $\mathrm{pH}$. The peptides resemble a cross- $\beta$-sheet-rich amyloid, and they assemble into a nanofibrous meshwork that mimics the natural extracellular matrix. Our design principle allows easy manipulation of the gelator sequence to exploit the desirable properties of amyloids for use in cell replacement therapies for neurodegenerative diseases. The amyloid hydrogels facilitate the attachment and neuronal differentiation of mesenchymal stem cells (MSCs) and assist in the delivery and engraftment of MSCs in the substantia nigra and caudate putamen of a Parkinsonian mouse model.

NPG Asia Materials (2016) 8, e304; doi:10.1038/am.2016.116; published online 9 September 2016

\section{INTRODUCTION}

Amyloids are highly ordered, self-assembled proteins/peptides that were originally implicated in several neurological disorders, such as Alzheimer's and Parkinson's disease, owing to their aberrant folding. ${ }^{1}$ However, amyloids are now recognized as a common protein structure with native biological functions in several host organisms ${ }^{2}$ including mammals, ${ }^{3}$ which support the survival of the host rather than being pathogenic. Irrespective of their toxic and functional roles, amyloid fibrils possess highly repetitive structures and are highly stable. These properties of amyloids make them attractive for designing various functional materials for nanotechnological/biotechnological applications. ${ }^{4-8}$ Moreover, the combination of hydrophobicity and charged residues (depending on the sequence) makes the surface of amyloid fibrils unique and enables them to bind to not only large macromolecules/polymers but also small molecules and cells. ${ }^{9-11}$

Cell transplantation holds great therapeutic potential for the regeneration of the central nervous system, but poor cell survival upon transplantation remains a significant problem. ${ }^{12-14}$ Moreover, the hostile environment of a diseased/damaged brain and lack of a proper microenvironment further limits cell viability. ${ }^{15}$ A suitable biomaterial can provide physical support, retain the cells in the implant and facilitate recovery. To this end, our group and several others have demonstrated that engineered amyloid fibrils support cell adhesion and growth. ${ }^{16-18}$ Recently, amyloid-based biomimetic hybrid materials have also been used for bone tissue engineering applications. ${ }^{19}$ We also previously designed self-healing amyloid hydrogels from the A 342 C-terminus that promote the adhesion and differentiation of mesenchymal stem cells (MSCs) in vitro. ${ }^{17}$ Notably, the higher-order alignment and unique mechanical strength of these amyloid hydrogels enable them to direct stem cell differentiation to neuronal lineages.

In this study, we harnessed the self-assembly behavior and physical properties of amyloid proteins and developed a series of hydrogels based on the self-recognition motif of $\alpha$-synuclein ( $\alpha$-Syn). These hydrogels were then tested for various applications in neural tissue engineering both in vitro and in vivo. The hydrogel promoted the differentiation of MSCs in vitro toward a neuronal lineage without the addition of growth factors. When human MSCs (hMSCs) were transplanted with our amyloid hydrogel into 1-methyl-4-phenyl-1, 2,3,6-tetrahydropyridine (MPTP) mice, the hydrogel was able to contain the cells at the transplant site, improve their survival and support neural differentiation.

\section{METHODS}

Chemical and reagents

All peptides were purchased commercially from GenPro, Noida, India and were of $98 \%$ purity. All other chemicals were purchased from Sigma Chemicals (St Louis, MO, USA) and were of the highest purity available. The chemicals used for cell culture are described in the respective sections.

Preparation of hydrogels

Briefly, $1 \mathrm{mg}$ of each peptide was dissolved in $200 \mu \mathrm{l}$ of $20 \mathrm{~mm}$ phosphate buffer at $\mathrm{pH} 7.4$ by heating the mixture on a burner. After three heating/cooling cycles

${ }^{1}$ IITB-Monash Research Academy, Indian Institute of Technology Bombay, Mumbai, India; ${ }^{2}$ Department of Biosciences and Bioengineering, Indian Institute of Technology Bombay, Mumbai, India; ${ }^{3}$ Department of Materials Science and Engineering, Monash Institute of Medical Engineering, Monash University, Clayton, Victoria, Australia; ${ }^{4}$ Australian Regenerative Medicine Institute, Monash University, Clayton, Victoria, Australia and ${ }^{5}$ Florey Institute of Neuroscience and Mental Health, The University of Melbourne, Parkville, Victoria, Australia

Correspondence: Dr JS Forsythe, Department of Materials Science and Engineering, Monash Institute of Medical Engineering, Monash University, Clayton, Victoria 3800, Australia. E-mail: john.forsythe@monash.edu

or Dr SK Maji, Department of Biosciences and Bioengineering, Indian Institute of Technology Bombay, Powai, Mumbai 400076, India.

E-mail: samirmaji@iitb.ac.in

Received 4 January 2016; revised 13 May 2016; accepted 6 June 2016 
and the addition of $150 \mathrm{~mm} \mathrm{NaCl}$, self-sustaining hydrogels were formed. For $\mathrm{A} 6$ and $\mathrm{A} 7$, the $\mathrm{pH}$ was increased to 10 to dissolve the peptides and subsequently decreased to 7.4 for gelation. A6 and A7 did not require the addition of salt for gelation.

\section{Thioflavin T (ThT)-binding assay}

For this assay, $10 \mu \mathrm{l}$ of a $1 \mathrm{~mm}$ ThT stock solution was added to $200 \mu \mathrm{l}$ of vortexed gel, and the solution was mixed thoroughly in a quartz cuvette. The fluorescence was measured immediately with a Shimadzu-RF-530 spectrofluorimeter (Kyoto, Japan) using excitation at $450 \mathrm{~nm}$, emission at $460-500 \mathrm{~nm}$ and a slit width of $3 \mathrm{~nm}$. ThT control experiment was carried out with $10 \mu \mathrm{l}$ of $1 \mathrm{mM}$ ThT dye solution in $200 \mu \mathrm{l}$ of phosphate buffer (20 mM, pH 7.4).

\section{Congo red (CR)-binding assay}

Fifteen microliters of CR stock solution ( $360 \mu \mathrm{M}$ stock) was mixed with $85 \mu \mathrm{l}$ of vortexed hydrogel and incubated in the dark for $5 \mathrm{~min}$. Ultraviolet (UV) absorption spectra were measured from 300 to $700 \mathrm{~nm}$ on a UV spectrophotometer (JASCO V-650, Tokyo, Japan). CR control experiment was done by incubating the dye solution with the buffer alone.

\section{Scanning electron microscopy}

Ten microliters of vortexed hydrogel were drop-cast on a glass coverslip and allowed to dry at room temperature. After two washes with Milli-Q water, the final dried samples were gold coated for $120 \mathrm{~s}$ at $10 \mathrm{mAmp}$ prior to scanning electron microscopy with a JSM-7600F (Peabody, MA, USA) at $5 \mathrm{kV}$.

\section{Scanning probe microscopy}

Ten microliters of vortexed gel sample were spotted on a freshly cleaved mica surface and air-dried. Atomic force microscopic imaging was conducted using a VeecoNanoscope IV (Santa Barbara, CA, USA) in tapping mode with a silicon nitride cantilever. Six different areas of each sample were scanned in triplicate at a scan rate of $1.5 \mathrm{~Hz}$.

\section{Fourier transform infrared spectroscopy (FTIR)}

Ten microliters of vortexed gel sample were spotted on a KBr pellet, and FTIR spectra were obtained using a Vertex 80 FTIR system equipped with DTGS detector (Bruker, Ettlingen, Germany). The spectra were acquired in the range of $1800-1500 \mathrm{~cm}^{-1}$ at a resolution of $4 \mathrm{~cm}^{-1}$ using an average of 32 scans.

Protein expression and purification and aggregation kinetics study Wild-type (WT) $\alpha$-Syn was expressed in Escherichia coli BL21(DE3) cells according to established protocols described by Volles et al. ${ }^{20}$ with slight modification. A low molecular weight solution and preformed fibrils of WT $\alpha$-Syn were prepared in $20 \mathrm{~mm}$ phosphate buffer containing $0.01 \%$ sodium azide at $\mathrm{pH} 7.4$ according to the protocol described by Ghosh et al. ${ }^{21}$ Preformed fibril seeds were prepared with a probe sonicator (Sonics \& Materials Inc., Newtown, CT, USA), which was operated at $20 \%$ amplitude for $3 \mathrm{~min}$ ( 3 pulse on $/ 1$ pulse off). Next $2 \%$ seed ( $\mathrm{v} / \mathrm{v})$ of both WT $\alpha$-Syn preformed fibril and hydrogel A5 fibril was added to $150 \mu \mathrm{l}$ of WT $\alpha$-Syn protein solution $(300 \mu \mathrm{M})$ to monitor the effect of gel fibril seeds and compared it with that of preformed fibril seeds. Protein fibrillation was monitored based on the fluorescence intensity of the fibril-binding dye ThT (excitation at $450 \mathrm{~nm}$ ) in a plate reader. ${ }^{22}$ As controls, seeds alone, WT $\alpha$-Syn low molecular weight alone and ThT alone were incubated under identical conditions. The obtained data (at $480 \mathrm{~nm}$ ) were fitted to a sigmoidal plot with Origin Pro (v8; Northampton, MA, USA).

For the seeding experiment with digested/degraded gel fibrils, $150 \mu \mathrm{l}$ of $300 \mu \mathrm{m}$ soluble $\alpha$-Syn was prepared, and 2\% (v/v) $\alpha$-Syn preformed fibril seed was added for the positive seeding reactions. Two different conditions were employed to study gel degradation in vitro. In one condition, phosphate buffer was placed on top of the gel surface (condition A) and incubated for up to 21 days. To mimic the possible degradation of the gel in vivo, the gel was mixed with $3.8 \mu \mathrm{g} \mathrm{ml}^{-1}$ proteinase $\mathrm{K}$ (the enzyme most frequently used for the nonspecific degradation of protein and amyloids ${ }^{23,24}$ ) and incubated for 21 days. After 7 and 21 days of incubation, $150 \mu \mathrm{l}$ of soluble $\alpha$-Syn was mixed with $3 \mu \mathrm{l}$ solution of phosphate buffer placed on the top (condition A) to achieve a $2 \% \mathrm{v} / \mathrm{v}$ concentration of degraded gel. A similar experiment was also performed with degraded gel in the presence of proteinase K (condition B). As controls, incubation were carried out for seeds alone, WT $\alpha$-Syn low molecular weight alone, degraded products from condition A alone, degraded products from condition B alone and ThT alone under identical conditions. The plot of ThT fluorescence at $480 \mathrm{~nm}$ were fitted to a sigmoidal plot with the Origin Pro (v8) software.

\section{Fluorenylmethyloxycarbonyl (Fmoc) fluorescence spectroscopy}

Fluorescence spectroscopy was performed with a Fluoromax-4 spectrofluorometer (Jovin Yovin, Edison, NJ, USA) equipped with a temperature controller. Scanning was performed from 80 to $25^{\circ} \mathrm{C}$ at an interval of $5^{\circ} \mathrm{C}$. The $200 \mu \mathrm{l}$ sample was excited at $265 \mathrm{~nm}$, and emission was recorded between 290 and $600 \mathrm{~nm}$. Both the excitation and emission slit widths were $5 \mathrm{~nm}$.

\section{Cell culture}

SH-SY5Y cells were cultured in Dulbecco's modified Eagle's medium (DMEM) (HiMedia, Mumbai, India) supplemented with $10 \%$ fetal bovine serum (HiMedia) and $1 \%$ antibiotic cocktail (HiMedia). The cells were cultured in a humidified chamber with $5 \% \mathrm{CO}_{2}$ and subcultured at $80 \%$ confluency.

\section{MTT (3-[4,5-dimethylthiazol-2-yl]-2,5 diphenyl tetrazolium bromide) assay}

Thirty microliters of each gel was placed onto three different wells in a 96-well plate (Costar, Corning Incorporated, Corning, NY, USA) and sterilized under UV for $30 \mathrm{~min}$. Approximately 10000 cells in $100 \mu \mathrm{l}$ complete medium were seeded per well and incubated for $24 \mathrm{~h}$. For another experiment, to study extended culture, this incubation was carried out for $120 \mathrm{~h}$ in a 24 well plate with $500 \mu \mathrm{l}$ complete media. After this incubation, $10 \mu \mathrm{l} \mathrm{MTT}\left(5 \mathrm{mg} \mathrm{ml}^{-1}\right.$ stock) was added, and the cells were further incubated for $4 \mathrm{~h}$. Finally, $100 \mu \mathrm{l}$ $50 \% \mathrm{~N}, \mathrm{~N}$-dimethylformamide $/ 20 \%$ sodium dodecyl sulfate solution was added, and the mixture was incubated overnight. The absorption was then measured at $560 \mathrm{~nm}$ with an automatic microtiter plate reader (Thermo Fisher Scientific, Waltham, MA, USA).

\section{Bone marrow-derived MSC culture on hydrogel}

Human bone marrow-derived MSCs were purchased from Stempeutics (Bangalore, India), and all experiments were performed with passage number 4-7 cells. Coverslips $(12 \mathrm{~mm}$ ) were treated with $0.5 \mathrm{~m} \mathrm{NaOH}$ for $30 \mathrm{~min}$, dried and coated with (3-aminopropyl) triethoxysilane (APES, Sigma) for $5 \mathrm{~min}$. The excess APES were removed by two washes with Milli-Q purified water. The coverslips were then dried inside a laminar flow hood, treated with $0.5 \%$ glutaraldehyde for $30 \mathrm{~min}$ and dried again. Dry coverslips were used for casting hydrogels. Briefly, $15 \mu \mathrm{l}$ of hydrogel was drop-cast on the coverslip and spread uniformly with the pipette tip. The hydrogels were prepared under the laminar flow and further sterilized under UV for $30 \mathrm{~min}$ after being cast on the coverslips. The coverslips with hydrogel were transferred into the wells of a 24-well plate (Nunc, Roskilde, Denmark), and $5 \times 10^{3}$ hMSCs were seeded in each well. Initially, a small volume (approximately $50 \mu \mathrm{l}$ ) of cell solution was used to ensure that the cells remain on the hydrogel. The remaining $200 \mu \mathrm{l}$ of complete media was added after $30 \mathrm{~min}$ of incubation. The cells were cultured in knockout DMEM (Gibco, Grand Island, NY, USA) supplemented with Glutamax (Gibco), 10\% fetal bovine serum (HiMedia) and $0.25 \%$ antibiotic cocktail (HiMedia) at $37^{\circ} \mathrm{C}$ in a humidified incubator with $5 \% \mathrm{CO}_{2}$. The medium was completely changed every third day. The control cells were incubated on glass coverslips only under identical conditions. Phase-contrast images of cells on the hydrogel and control were obtained every other day using an Olympus IX-50 microscope (Tokyo, Japan) at $\times 10$ magnification. The images were analyzed with the ImageJ software (Bethesda, MD, USA) to obtain the cell spread area and circularity, and box whisker plots were generated for cell circularity using OriginPro (v8). 


\section{$3 \mathrm{D}$ cell viability assay}

For the 3D culture, the A5 gel was briefly vortexed, and 5000 SH-SY5Y cells were promptly mixed with $50 \mu \mathrm{l}$ of gel. The system then was allowed to gel for $15 \mathrm{~min}$ in a 96-well plate, and the cells were incubated in complete medium for $24 \mathrm{~h}$ at $37^{\circ} \mathrm{C}$ in a humidified chamber. After incubation, the medium was removed, and the cells were treated with $1 \mu \mathrm{M}$ Calcein-AM for $20 \mathrm{~min}$ in the dark before being imaged with an Olympus IX-50 microscope at $\times 10$ magnification.

An ATP-based cell viability assay was conducted using a CellTiter-Glo 3D Cell Viability Assay Kit (Promega Corporation, Madison, WI, USA). Briefly, the cells were cultured in 3D A5 hydrogel as mentioned above, and the control cells were cultured in 3D collagen hydrogel. To prepare the 3D collagen gel, highprotein collagen type I solution (Sigma) was added to $10 \times$ phosphate-buffered saline (PBS) solution (HiMedia) at $4{ }^{\circ} \mathrm{C}$. Plain DMEM (Invitrogen, Carlsbad, CA, USA) was subsequently added, and the $\mathrm{pH}$ was adjusted to 7.2 using $1 \mathrm{~N}$ $\mathrm{NaOH}$ solution. Following incubation on ice for $10 \mathrm{~min}, 5000$ cells were added to $50 \mu \mathrm{l}$ collagen solution. For the polymerization reaction, the cell and gel mixture was incubated at $37^{\circ} \mathrm{C}$ for $45 \mathrm{~min}$ in a 96-well plate. Subsequently, $100 \mu \mathrm{l}$ of complete DMEM was added, and the cells were incubated for $120 \mathrm{~h}$. All samples were tested in triplicate. After incubation, the plate and assay reagent were equilibrated at room temperature for $30 \mathrm{~min}$. Subsequently, $100 \mu \mathrm{l}$ of CellTiter-Glo Assay reagent was then added to each well, and the solution was mixed thoroughly with a pipette. The hydrogel was disrupted with a micropipette tip to allow the added reagent to access cells inside the hydrogel. The contents of the plate were then vigorously mixed for $5 \mathrm{~min}$ on a rocker to induce cell lysis and further incubated for $30 \mathrm{~min}$ at room temperature to stabilize the signal. Luminescence was recorded on a Spectramax M5 microplate reader (Molecular Devices, Sunnyvale, CA, USA) with an integration time of $1000 \mathrm{~ms}$. The cell viability was plotted according to manufacturers protocol.

\section{Rheological measurements}

Rheological measurements were performed using an Anton Paar rheometer (Graz, Austria) with a parallel plate (diameter of $25 \mathrm{~mm}$; PP25). Two hundred microliters of preformed hydrogel were loaded between the plates for the study. The measurements were taken at $37^{\circ} \mathrm{C}$ in dynamic oscillatory mode with a constant amplitude of $0.05 \%$ and a gap size of $0.2 \mathrm{~mm}$. The frequency sweep was performed with an angular frequency $(\omega)$ of $100-0.11^{-1}$ for $15 \mathrm{~min}$. The linear viscoelastic region was determined from a preliminary strain sweep from $0.01 \%$ to $100 \%$ at a constant frequency. For the step-strain oscillatory rheology, an identical setup was used. A high strain $(100 \%)$ was applied to the gel to disrupt it and was subsequently allowed to recover under low strain $(0.5 \%)$. The storage modulus (G') and loss modulus (G') were recorded and plotted as a function of time over three cycles of decay and recovery.

\section{RNA isolation and quantitative real-time PCR}

hMSCs were cultured on hydrogels and glass coverslips for $120 \mathrm{~h}$ in complete medium. RNA was isolated using TRIzol reagent (Invitrogen, Carlsbad, CA, USA) according to the manufacturer's protocol. Total RNA was then reverse transcribed to cDNA with a ProtoScript First Strand cDNA Synthesis Kit (NEB, Ipswich, MA, USA) using random hexamers and Oligo(dT) 20 primers according to the manufacturer's protocol. Real-time PCR was performed using SYBR Green Master Mix (Ambion, Carlsbad, CA, USA) on an Illumina Eco qPCR system (San Diego, CA, USA). Predesigned validated SYBR green primers were purchased from Sigma-Aldrich (Bangalore, India) for the study.

\section{Hydrogel implantation into the rat brain}

All animal experiments were approved by the Howard Florey Institute Ethics committee and were in accordance with the National Health and Medical Research Council guidelines. The animals were housed two rats per cage, given free access to food and water and kept on a 12/12 h light/dark cycle. Rats were administered an intramuscular injection of a predrug mix consisting of $0.1 \mathrm{ml}$ atropine and $0.2 \mathrm{ml}$ xylazine diluted in $0.7 \mathrm{ml}$ saline. Anesthesia was induced with $3 \%$ isofluorane in oxygen at a constant flow rate of $1.01 \mathrm{~min}^{-1}$. When unresponsive to a toe pinch, the head was shaved, and the rats were placed into a stereotaxic instrument before exposing the skull. Bilateral craniotomies were performed at the following coordinates: anteroposterior $+1.0 \mathrm{~mm} \mathrm{AP}$ and lateral $+2.5 \mathrm{~mm}$ ML (medial-lateral) from the bregma. A $32 \mathrm{~mm} 21 \mathrm{G}$ needle preloaded with the hydrogel was loaded onto the stereotactic frame, and the hydrogel was implanted into the brain to a depth of $-7.0 \mathrm{~mm} \mathrm{DV}$ (dorsal-ventral). Phosphate buffer $(20 \mathrm{~mm})$ was implanted as a control. For each rat $(n=3)$, the hydrogel was implanted in the right hemisphere, and a control was implanted on the left. The experiments were set for two time points, 7 and 21 days. After surgery, an antiseptic ointment was applied to the edges of the wound, which was sutured. The rats were allowed to fully recover in warm cages prior to being returned to their home cages.

\section{Immunohistochemistry}

Rats were killed by cardiac perfusion under terminal anesthesia with $0.1 \mathrm{ml}$ Lethabarb and ice-cold saline, followed by $4 \%$ paraformaldehyde solution. After removing the brain, it was equilibrated with $30 \%$ sucrose, and $30 \mu \mathrm{m}$ transverse sections were obtained on a cryostat. The sections were then permeabilized with $0.5 \%$ Triton X-100, blocked with $10 \%$ normal goat serum $+1 \%$ bovine serum albumin $+0.2 \%$ Tween 20 and incubated with rabbit monoclonal primary antibodies against glial fibrillary acidic protein (GFAP; 1:1000; DAKO, Sydney, NSW, Australia) and IBA1 (1:250; Wako Pure Chemical Industries, Osaka, Japan). Alexa Fluor 488 and 568 (1:1000; Molecular Probes, Eugene, OR, USA, Invitrogen) were used as secondary antibodies, and $0.5 \%$ Thioflavin-S (Sigma Chemicals, Bangalore, India) in Milli-Q water was used to stain the amyloid components of the sections. The nuclei were counterstained with DAPI $(4,6-$ diamidino-2-phenylindole). Images were then obtained with a Nikon Eclipse Ti-U fluorescent microscope (Tokyo, Japan) at $\times 10$ magnification. The total fluorescent intensity obtained from each channel was quantified for an area of approximately $500 \mu \mathrm{m}$, with the implant at the center for both hydrogelcontaining and sham sections. The background signal was reduced by measuring the intensity of five random fields in the region of interest. At least five different sections were analyzed for quantification.

\section{Priming green fluorescent protein (GFP)-tagged hMSCs (GFP-hMSCs)}

hMSCs expressing enhanced GFP were purchased from the Tulane Centre for Stem Cell Research and Regenerative Medicine and cultured in medium consisting of $\alpha$-Minimum Essential Medium supplemented with $16.5 \%$ fetal bovine serum, $2 \mathrm{~mm}$ L-glutamine, $100 \mathrm{U} \mathrm{ml}^{-1}$ penicillin and $100 \mu \mathrm{g} \mathrm{ml}^{-1}$ streptomycin (all reagents were purchased from Invitrogen). The GFP-hMSCs were passaged at $80 \%$ confluency using Tryple (Invitrogen). The hMSCs (P6-P8) were primed to induce differentiation into dopaminergic neurons (DA neurons) with neurobasal medium supplemented with $0.25 \times \mathrm{B} 27, \quad 250 \mathrm{ng} \mathrm{ml}^{-1} \mathrm{SHH}, \quad 100 \mathrm{ng} \mathrm{m}^{-1}$ fibroblast growth factor (FGF)-8 and $50 \mathrm{ng} \mathrm{ml}^{-1}$ FGF-2.

\section{Generation of MPTP mice and implantation of cells}

MPTP was administered to 5-month-old C57BL/6 male mice at a total dose of $60 \mathrm{mg} \mathrm{kg}^{-1}$ per mouse. The dose was divided into four intraperitoneal injections, $2 \mathrm{~h}$ apart. This dosage resulted in a $45 \%$ loss of substantia nigra (SN) pars compacta cells, as counted by stereology. For the cell implantation surgery, each animal was given an intraperitoneal injection containing $6 \mu \mathrm{g}$ atropine, $400 \mu \mathrm{g}$ xylazine and $50 \mu \mathrm{g}$ meloxicam in $0.2 \mathrm{ml}$ of saline. The animals were then placed in a nose cone with $3 \%$ isoflurane in oxygen at a flow rate of $1.51 \mathrm{~min}^{-1}$ and anesthetized. The scalp was parted with an incision, and a burr hole was drilled $2.7 \mathrm{~mm}$ anterior and $1.8 \mathrm{~mm}$ lateral to the bregma on either hemisphere. A $23 \mathrm{G}$ needle preloaded with cells (and gel) was inserted at an angle of $55^{\circ}$ (from vertical) to a depth of $6 \mathrm{~mm}$ from the cortical surface for implantation in the SN pars compacta and a reduced depth $(3 \mathrm{~mm})$ for implantation in the caudate putamen. A suitable plunger was used to deliver the contents of the needle to the target site. The arrangement was left undisturbed for $5 \mathrm{~min}$ to minimize the backflow of the cells through the delivery vehicle. The wound was closed using cyanoacrylate glue. Three animals were used to test each implant site. Cells cultured in TC flasks were detached with Tryple express (Invitrogen) before being pelleted, counted and mixed with A5 hydrogel at a density of 50000 cells per $25 \mu$ l of hydrogel. Subsequently, $10 \mu \mathrm{l}$ of this cell-gel solution was loaded into a $23 \mathrm{G}$ needle using a P10 pipette. 
a $1-60$ $\alpha$-synuclein 61-95

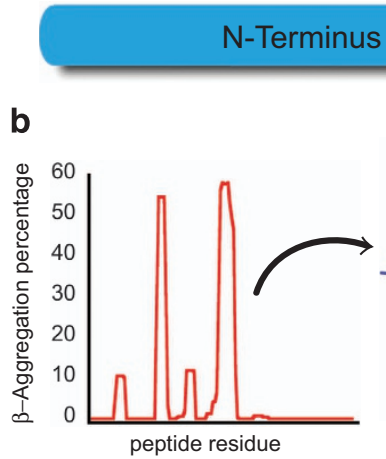

\section{NAC} C-Terminus

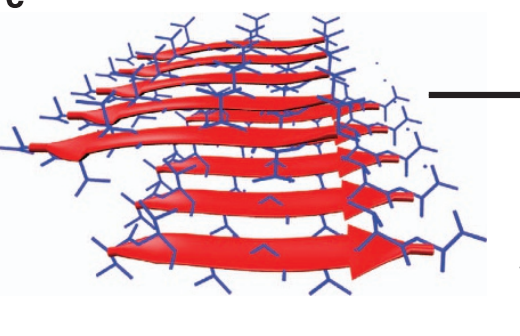

d<smiles>CC(NC(=O)C(NC(=O)C(NC(=O)C(NC(=O)C(N)C(C)C)C(C)O)C(C)C)C(C)O)C(=O)O</smiles>
$\alpha$-syn (74-78)
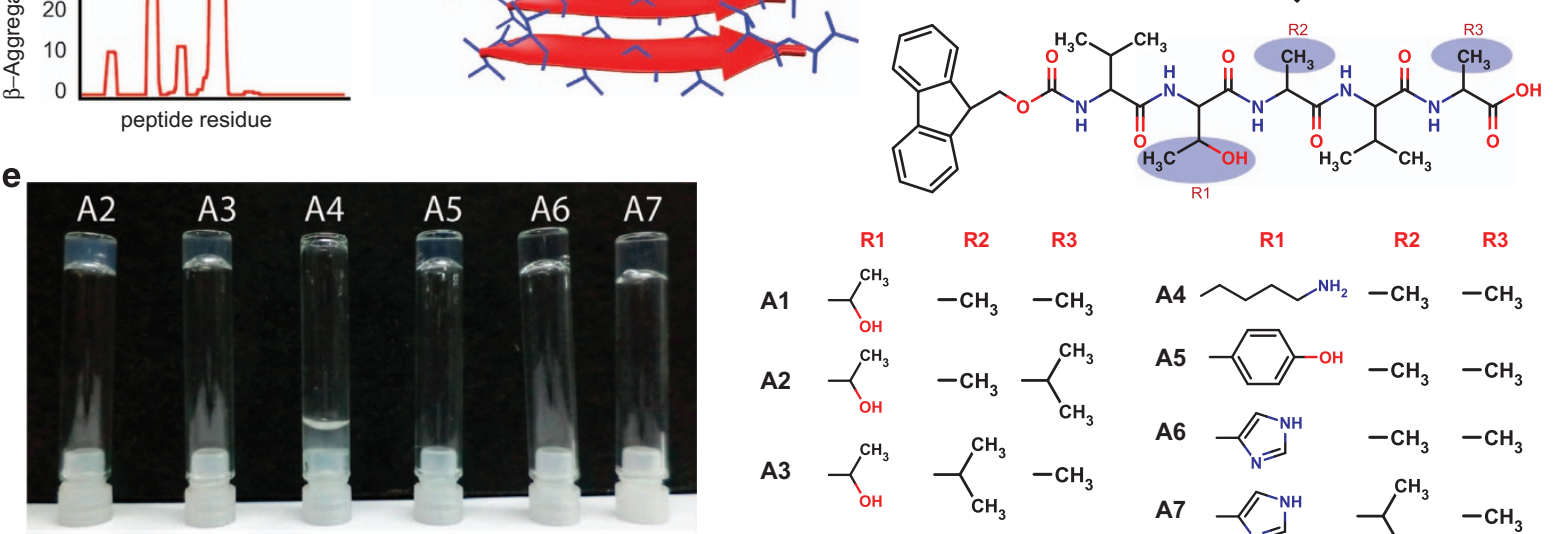

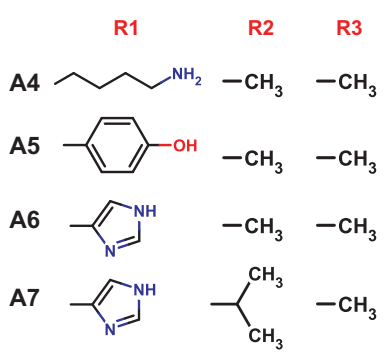

Figure 1 Design and synthesis of amyloid hydrogels. (a) Schematic depicting the different domains of full-length $\alpha$-Syn protein. (b) TANGO plot of $\alpha$-Syn showing the $\beta$-aggregation-prone regions of $\alpha$-Syn. (c) Crystal structure of $\alpha$-Syn(70-76) (PDB ID: 4ROW) ${ }^{57}$ amyloid microcrystal showing cross $\beta$-sheet arrangement. (d) Peptide design based on the high amyloidogenic region of $\alpha$-Syn for hydrogels. Three different side chains were judiciously altered (depicted as R1, R2 and R3) to design various hydrogels. The changes in the amino-acid side chains for various peptides are shown. (e) The hydrogels formed by various peptides shown by using a gel inversion test. A4 did not form a hydrogel.

The harvested brains were immersed in $4 \%$ paraformaldehyde and equilibrated with $30 \%$ sucrose, and $20 \mu \mathrm{m}$ coronal sections were obtained with a cryostat. The implanted number of cells and the area occupied by the transplanted cells were quantified using ImageJ. At least five different sections were analyzed for each implantation site.

\section{Statistical analysis}

The significance of differences was statistically tested with a one-way analysis of variance, followed by a Newman-Keuls multiple comparison post-hoc test; ${ }^{*} P$-values for each graph/plot are mentioned in the corresponding figure legends.

\section{RESULTS}

\section{Design of gelators and biophysical characterization}

$\alpha$-Syn is a 140 amino-acid protein (Figure 1a) that contains numerous regions of varying amyloidogenicity and exhibits a high propensity for $\beta$-sheet formation (Figures $1 \mathrm{~b}$ and $\mathrm{c}$ ). The sequence-dependent amyloid propensity of the full-length protein was predicted using the software TANGO, which showed several small segments of varying amyloidogenicity. However, the most $\beta$-aggregation-prone region (74-78), which contains the sequence VTAVA within the NAC region of $\alpha$-Syn, was selected for the design of hydrogels. The $\mathrm{N}$-terminus of the peptide was protected with a Fmoc group, which is known to enhance the intermolecular $\pi$-stacking interactions. This peptide is henceforth named A1. The amino-acid sequences of A1 were then altered (Figure 1d) such that the resulting peptide would have sufficient hydrophobic or $\pi$ stacking interactions to support selfassembly under suitable conditions.
To generate A2 and A3, Ala was substituted at the fifth and third position of the core gelator sequence VTAVA with Val, which is more hydrophobic than Ala. A5 was designed by replacing Thr with Tyr at the second position, which would enhance stacking interactions between the peptides. When the peptides were dissolved in physiological buffer condition (20 mm phosphate buffer, $\mathrm{pH} 7.4$ ), peptides A2, A3 and A5 formed self-supporting hydrogels (Figure 1e) at a concentration of $6 \mathrm{mg} \mathrm{ml}^{-1}$ after repeated heating and cooling cycles and in the presence of $150 \mathrm{~mm} \mathrm{NaCl}$. Al did not form a hydrogel under the tested conditions. To further develop $\mathrm{pH}$-responsive hydrogels, residues whose side chain ionization would vary according to the $\mathrm{pH}$ of the buffer were introduced to the core sequence of Fmoc-VTAVA. To this end, Thr was substituted with Lys in A1 to produce A4; Thr was replaced with His in A1 and A3 to produce A6 and A7, respectively (Figure 1d). A4 did not dissolve in $20 \mathrm{~mm}$ phosphate buffer at $\mathrm{pH} 7.4$ but dissolved above $\mathrm{pH}$ 10.4. However, this peptide did not form a hydrogel when the $\mathrm{pH}$ was lowered further or after repeated heating and cooling cycles. Both A6 and A7 also dissolved at approximately $\mathrm{pH} 10$ and formed hydrogels when the $\mathrm{pH}$ was lowered to 7.4. The presence of salt is essential for A2, A3 and A5 to form hydrogels, suggesting that the salt shields the C-terminal negative charge to favor self-assembly and gelation. This suggestion is further supported by the generation of higher-modulus hydrogels upon the addition of a bivalent cation $\left(\mathrm{Ca}^{2+}\right)$ to $\mathrm{A} 5$ and $\mathrm{A} 6$ compared with the addition of a monovalent cation $\left(\mathrm{Na}^{+}\right)(20 \mathrm{~Pa}$ in $\mathrm{NaCl}$ compared with $90 \mathrm{~Pa}$ in $\mathrm{CaCl}_{2}$ ) (Figure 2a). Interestingly, the formation of hydrogels by A6 and A7 did not require the addition of $\mathrm{NaCl}$, suggesting that a neutralizing $\mathrm{pH}$ is sufficient for the 

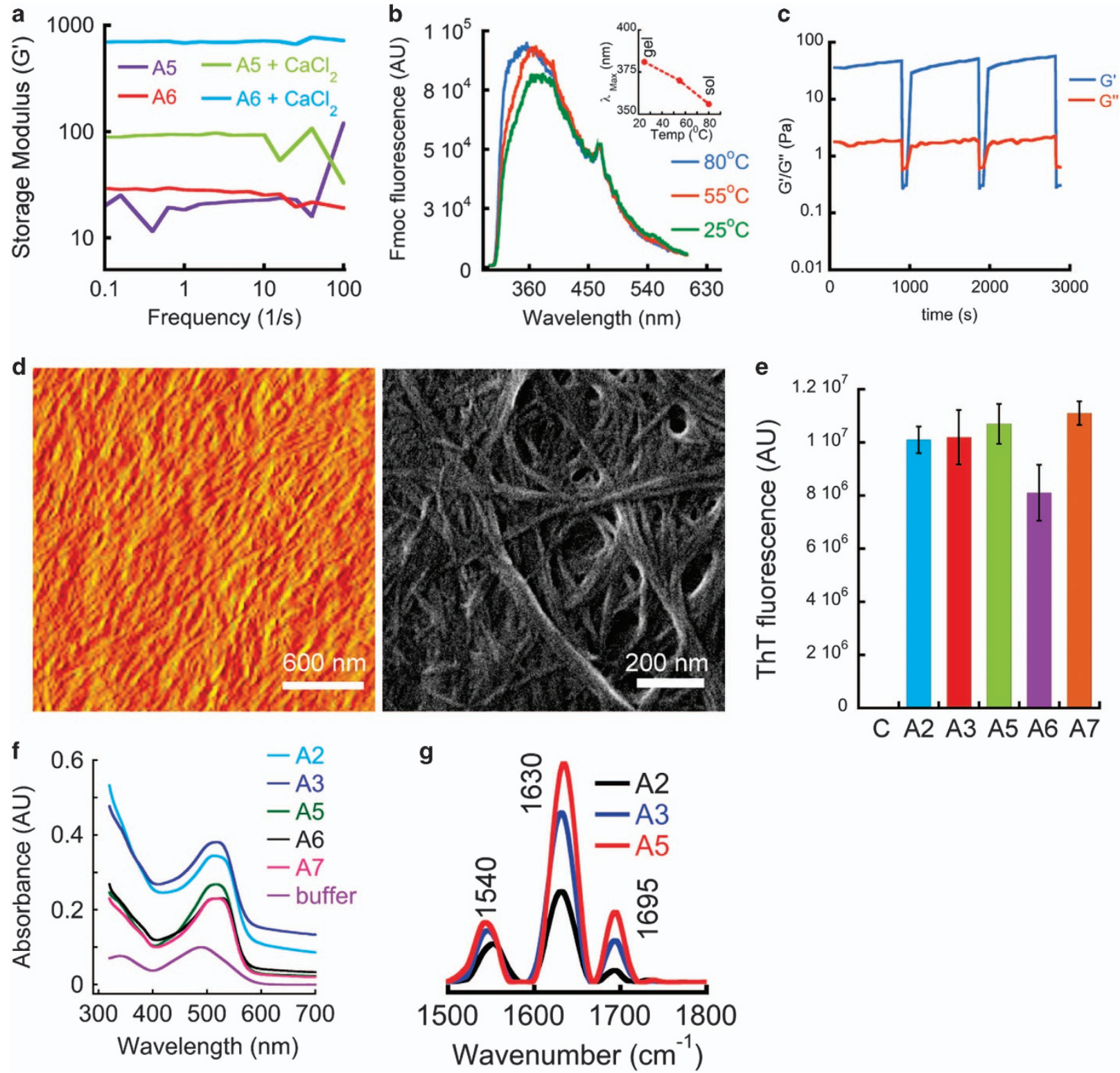

Figure 2 Physical properties of amyloid hydrogels. (a) Plot of the storage modulus ( $G$ ') vs the frequency of the hydrogels. The addition of CaCl 2 increased the moduli of the hydrogels. (b) The temperature-dependent Fmoc fluorescence of hydrogel $\mathrm{A} 5$ from 80 to $25^{\circ} \mathrm{C}$. The inset shows a red shift of peaks due to $\pi$ - $\pi$ stacking during the lowering of temperature. (c) The oscillatory rheology with cyclic $100 \%$ and $0.5 \%$ strain at a constant frequency of 1 Hz shows that hydrogel A5 is self-healing. (d) Morphological characterization of the dried A5 hydrogel using AFM (left) and SEM (right) showing the dense fibrillar networks responsible for gel formation. Scale bar for AFM is $600 \mathrm{~nm}$ and SEM is $200 \mathrm{~nm}$. (e) Thioflavin T (ThT) fluorescence of all hydrogels. The high intensity of ThT florescence at $480 \mathrm{~nm}$ after binding to the hydrogels indicates the presence of amyloid fibrils in the hydrogels. 'C' represents ThT binding to buffer. (f) Congo red absorption plot of all hydrogels depicting a red shift and increased absorption at $520 \mathrm{~nm}$, which indicates the amyloidogenic nature of hydrogels. (g) Peaks at the amide-I region at approximately 1630 and $1690 \mathrm{~cm}^{-1}$ of the FTIR spectra depicting a signature typical of cross $\beta$-sheet structures ${ }^{28}$ for thermo-responsive amyloid hydrogels.

self-aggregation by these peptides. Gel formation could be further assisted by the enhanced stacking interaction between the imidazole side chain of His, making the requirement of salts redundant. The viscoelastic properties of these hydrogels were assessed with oscillatory rheology. Specifically, the storage modulus was $20 \pm 4 \mathrm{~Pa}$ for the thermo-reversible hydrogel $\mathrm{A} 5$ and $28 \pm 5 \mathrm{~Pa}$ for the $\mathrm{pH}$-responsive hydrogel A6 (Figure 2a).

Because the peptide versions of A2, A3, A5, A6 and A7 without the Fmoc group did not exhibit gelation, we propose that self-assembly in this peptide system may also be driven by the $\pi-\pi$ stacking of Fmoc groups because Fmoc peptides were previously reported to drive self-assembly via the $\pi-\pi$ stacking of the Fmoc moiety. ${ }^{25}$ To further confirm the participation of intermolecular Fmoc interactions in gelation, the A5 hydrogel was examined with fluorescence spectroscopy during gelation. Specifically, a reduction in fluorescence intensity and concomitant $\lambda_{\max }$ red shift are associated with the stacking of Fmoc groups during the gelation of Fmoc peptides. Using temperature-dependent gelation, Fmoc fluorescence was recorded by exciting the sample at $265 \mathrm{~nm}$ and observing emission in the range of $290-500 \mathrm{~nm}$. At $80^{\circ} \mathrm{C}$, the peptide solution showed Fmoc fluorescence, and the fluorescence maximum was obtained at $356 \mathrm{~nm}$. When the peptide solution was allowed to form a gel by 
a
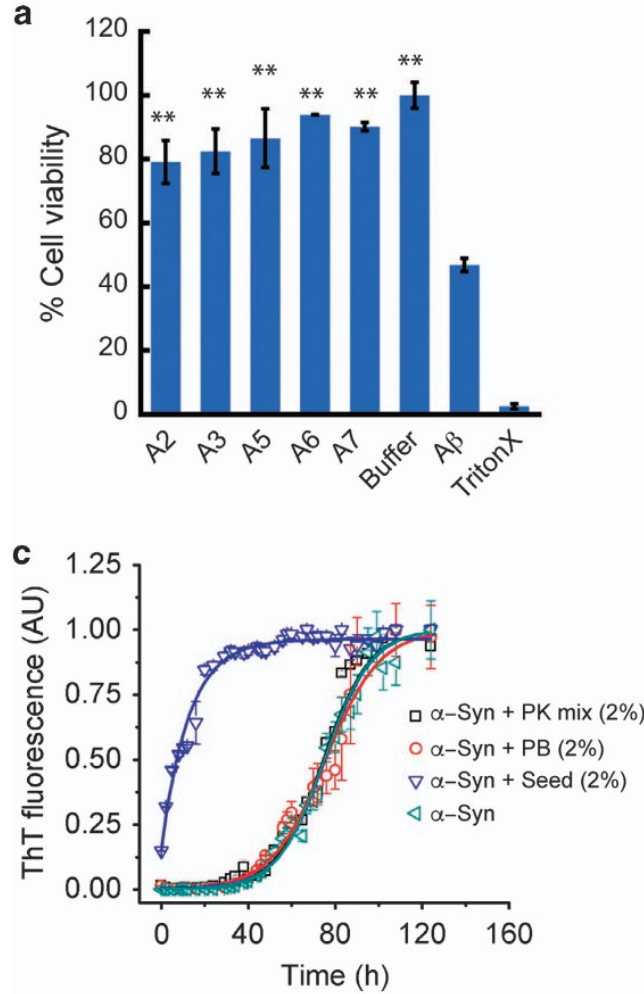

e

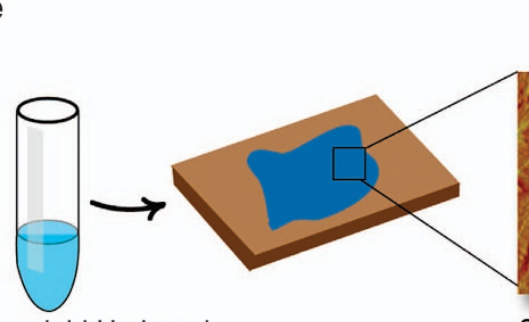

Amyloid Hydrogel

f

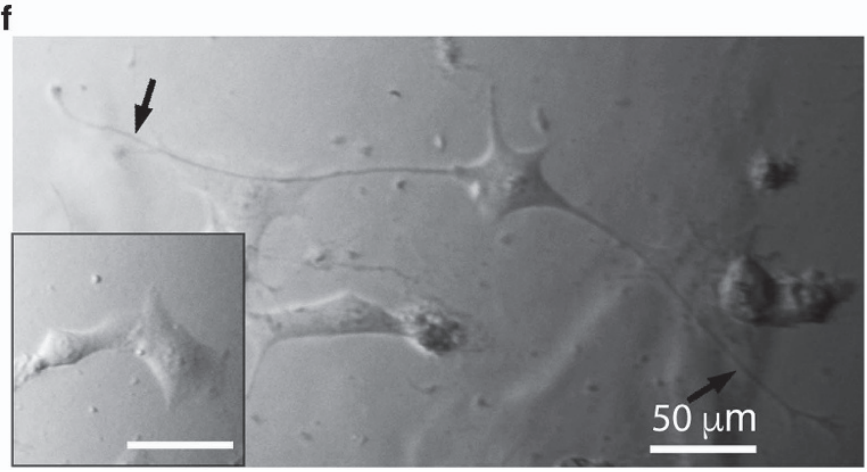

b
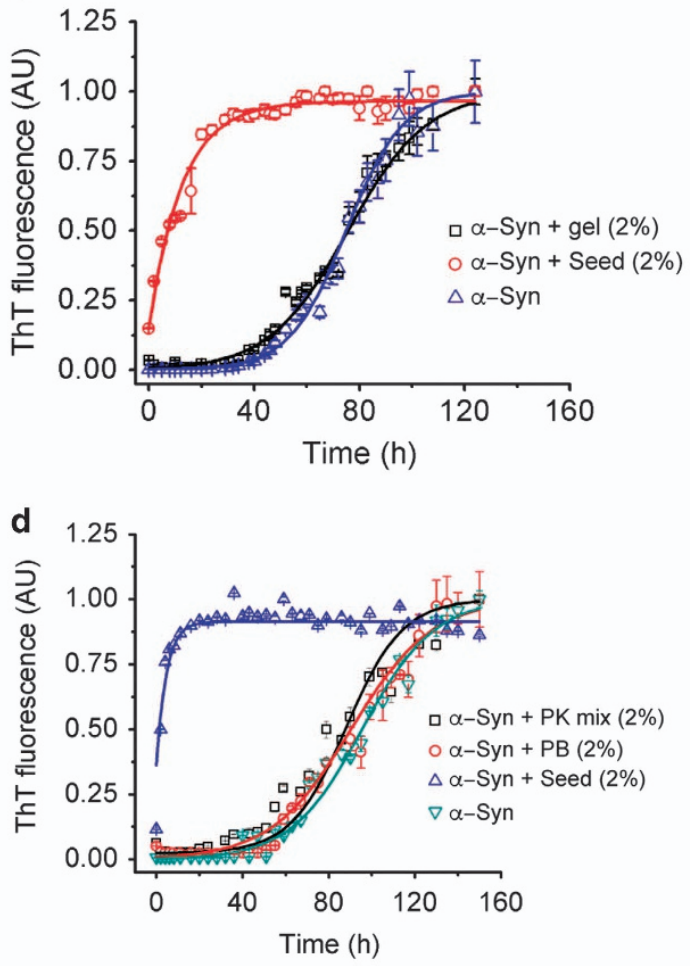
gradual cooling, the $\lambda_{\max }$ exhibited a red shift and the Fmoc fluorescence intensity decreased. At $25^{\circ} \mathrm{C}$ in the gel state, the fluorescence intensity had decreased from approximately 95000 $(\mathrm{AU})$ to 82000 (AU) and exhibited an approximately $20 \mathrm{~nm}$ redshift (Figure 2b), which was likely due to a fluorenyl excimer species. Therefore, the present data suggest that the $\pi-\pi$ stacking of the fluorenyl group may be extensive and have a significant role in the gelation of this peptide.

To demonstrate thixotropicity, the hydrogels (A2, A3, A5, A6 and A7) were vortexed for $15 \mathrm{~s}$ to cause a transition to solution, which was confirmed by visual inspection and a gel inversion test (Supplementary Figure S1). When undisturbed for $20 \mathrm{~min}$, all solutions reverted back to the gel state except for A3, which recovered in $35 \mathrm{~min}$. To further demonstrate thixotropicity, hydrogel A5 was examined with step-strain oscillatory rheology (Figure 2c). Following the application of a high strain $(100 \%)$ to the gel, the storage modulus $\left(G^{\prime}\right)$ dropped below the loss modulus (G') (sol state), which was attributed to the disruption of the gel network. After releasing the strain, the gel recovered under a low strain $(0.5 \%)$, and the G' increased above the G'. Three cycles of shear stress and recovery were performed, confirming the shear thinning behavior of hydrogel A5.

To study the meshwork responsible for water entrapment and gelation, the dried hydrogels were subjected to field emission gun scanning electron microscopy (Figure 2d and Supplementary Figure S2) and atomic force microscopy (Figure $2 \mathrm{~d}$ and Supplementary Figure S3A). Both techniques revealed that the peptides self-assemble into nanofibrils with a diameter of approximately $40 \mathrm{~nm}$ and height of approximately $10 \mathrm{~nm}$ (Supplementary Figure S3B). To study whether gel formation from these peptides is governed by amyloid aggregation, assays using the amyloid-detecting dyes ThT and CR were performed. ThT is a fluorescent dye widely used to ascertain the amyloidogenicity of proteins/peptides, because it specifically binds to the $\beta$-sheet structure of amyloid fibrils and not to the monomeric form of the proteins/peptides. ${ }^{26}$ Thus A2, A3, A5, A6 and A7 were subjected to a ThT-binding assay. The high ThT fluorescence at $480 \mathrm{~nm}$ suggests that the fibril networks of these peptide hydrogels are amyloidogenic in nature (Figure 2e). The amyloidogenicity of the gel fibril network was further supported by the high binding of another amyloid dye, CR, which generated an increase in the absorbance upon interacting with the hydrogels (Figure 2f). Because aggregates of amyloid protein and peptide consist of a cross- $\beta$-sheet-rich structure, ${ }^{11,27}$ the secondary structure of the peptides in the hydrogels was assessed using FTIR spectroscopy. ${ }^{28}$ The FTIR peaks at approximately 1630 and $1690 \mathrm{~cm}^{-1}$ in the amide I (1600-1700 $\mathrm{cm}^{-1}$ ) region confirmed the presence of cross $\beta$-sheet structures in the gel (Figure $2 \mathrm{~g}$ and Supplementary Figure S4).

\section{Toxicity and seeding capacity of amyloid hydrogels}

Because the present class of hydrogels consists of amyloid fibrils, and certain amyloids are known to be toxic to cells, ${ }^{29}$ the viability of SH-SY5Y cells seeded on the hydrogels was evaluated using an MTT assay. ${ }^{30}$ All hydrogels supported cell survival $>80 \%$ (Figure 3a). To assess the long-term effects of these hydrogels on cell viability, we subjected SH-SY5Y cells cultured on hydrogel A5 for $120 \mathrm{~h}$ to an MTT assay. These cells exhibited a viability of $87 \pm 7 \%$, which was similar to the viability observed after $24 \mathrm{~h}$ of incubation $(88 \pm 2 \%)$ (Supplementary Figure S5).

Recently, $\alpha$-Syn fibrils were suggested to be infectious in a manner similar to prions. Specifically, preformed $\alpha$-Syn fibrils/seeds recruit soluble $\alpha$-Syn monomers and transform them to insoluble fibrils by accelerating the fibrillation process. ${ }^{31,32}$ To assess whether the gel fibrils possess similar seeding properties, we performed an in vitro aggregation kinetics experiment with soluble $\alpha$-Syn protein using gel fibrils as seeds. Full-length $\alpha$-Syn fibril seeds were used as a positive control. Specifically, fibril seeds were incubated in a WT $\alpha$-Syn protein solution at $37^{\circ} \mathrm{C}$ with slight agitation, and ThT fluorescence was monitored at regular time intervals. $\alpha$-Syn aggregation using ThT fluorescence demonstrated the sigmoidal growth of fibril formation, which exhibited three distinct phases. The first phase was a lag phase, followed by an exponential growth phase that finally reached a saturation phase (Figure 3b). Because the lag phase is the ratelimiting step of fibril formation, the effect of kinetics on fibril formation is most often represented by the change in the lag time. ${ }^{33}$ Therefore, a reduction in lag time represents a positive seeding effect. In our experiment, the lag time was calculated by fitting established equations to the curve. ${ }^{34}$ The ThT fluorescence data, which represented the kinetics in the presence and absence of seeds, showed that gel fibrils did not affect the aggregation of WT $\alpha$-Syn protein. In contrast, preformed fibril seeds from full-length protein aggregated WT $\alpha$-Syn protein much faster, as evidenced by the undetectable lag time (Figure $3 b$ ).

Although the fibrils constituting hydrogel A5 do not seed full-length $\alpha$-Syn, its degraded products may lead to the generation of fragments that may interact with $\alpha$-Syn and modulate its aggregation state over time. To evaluate this effect, aggregation kinetics experiments were performed using two different conditions for gel degradation in vitro. In one condition, phosphate buffer was placed on top of the gel surface (condition A), and the gel was then incubated up to 21 days. To mimic the degradation of the gel in vivo, the gel was further mixed with $3.8 \mu \mathrm{g} \mathrm{ml}^{-1}$ proteinase $\mathrm{K}$, an enzyme most frequently used for the non-specific degradation of proteins and amyloids ${ }^{23,24}$ (condition B), and incubated for 21 days. After 7 and 21 days of incubation, 2\% $\mathrm{v} / \mathrm{v}$ degraded gel products from both conditions A and B were added to WT $\alpha$-Syn, and aggregation was monitored via ThT fluorescence (Figures $3 \mathrm{c}$ and d). At 7 days, no significant change in the lag time was observed for $\alpha$-Syn aggregation under the different conditions (seeding with conditions A and B produced lag times of $47 \pm 2.6$ and $47 \pm 2.5 \mathrm{~h}$, respectively, and $\alpha$-Syn alone exhibited a lag time of $49 \pm 0.8 \mathrm{~h}$; Supplementary Figure S6). A similar trend was observed at 21 days for $\alpha$-Syn alone, which exhibited a lag time of $57 \pm 1.2 \mathrm{~h}$; for seeding with gel fragments from conditions $\mathrm{A}$ and $\mathrm{B}$, the lag times were $55 \pm 2$ and $58 \pm 2 \mathrm{~h}$, respectively (Supplementary Figure S7). Therefore, neither gel fibrils nor their degraded counterpart possess any seeding capacity for $\alpha$-Syn fibrillation. However, WT $\alpha$-Syn fibril seeds were able to almost eliminate the lag time for aggregation in all cases.

\section{Cell responses to amyloid hydrogels}

To study the cellular response on the amyloid hydrogels, 2D cell culture experiments were performed. Specifically, SH-SY5Y cells were cultured on amyloid hydrogels, and all hydrogels supported cell attachment and survival without the need for cell adhesion motifs, such as RGD (Figures $3 \mathrm{e}$ and $\mathrm{f}$ and Supplementary Figure S8). The cells cultured on the hydrogel were elongated, whereas cells cultured on the glass control exhibited more spreading. Following $48 \mathrm{~h}$ of culture, gel A5 promoted more neurite extension than the glass control (Figures $3 \mathrm{f}$ and g). After $120 \mathrm{~h}$ of culture, a network of neurites was evident in SH-SY5Y cells cultured on A5, whereas the control exhibited spindle-shaped cells (Supplementary Figure S9). We hypothesized that the neuronal morphology and accompanying increased neurite outgrowth could be due to the modulus of the gel because soft hydrogels are well known to promote neuronal 
a
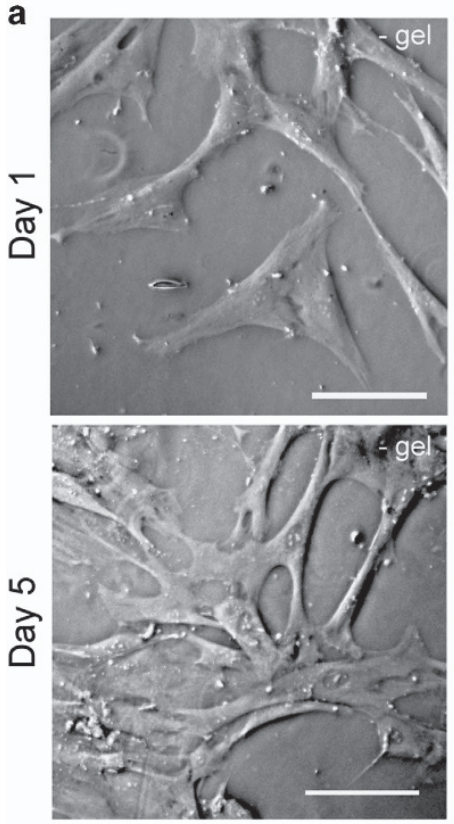
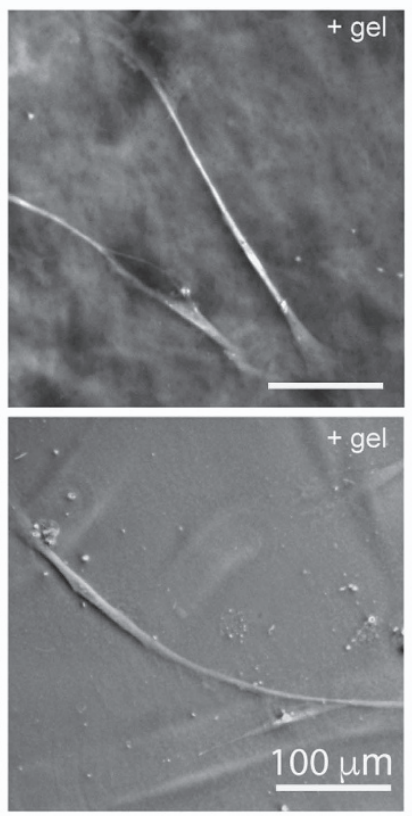

b
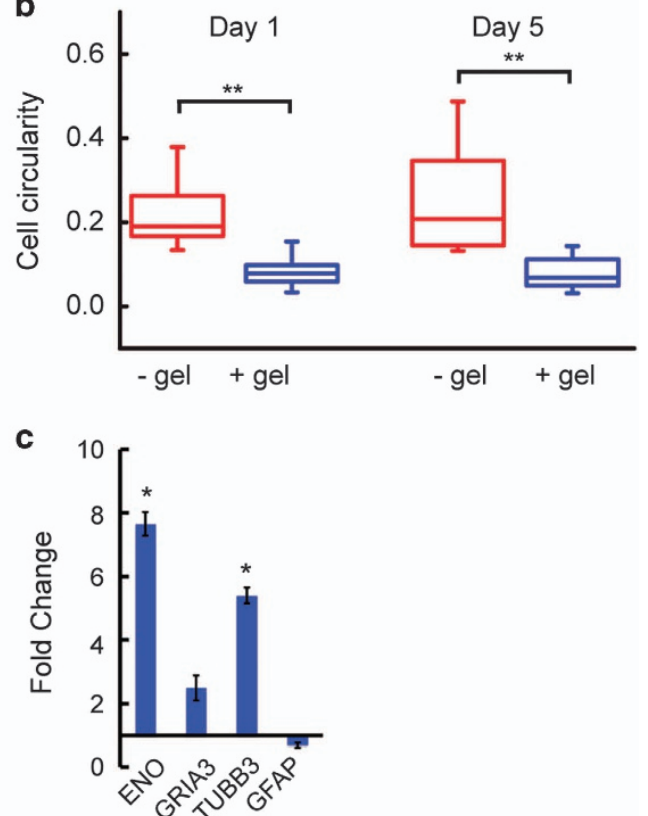

Figure 4 Differentiation of mesenchymal stem cells with amyloid hydrogels. (a) Morphology of hMSCs after culture on hydrogel A5 (+gel) and glass coverslips (-gel). Cells after 5 days of culture on A5 showing elongated bipolar morphology. The scale bars represent $100 \mu \mathrm{m}$. (b) Quantification of the circularity of hMSCs cultured on A5 compared with control glass. Bars indicate significance ( $\left.{ }^{* *} P<0.005\right)$. (c) Quantitative real-time PCR showing the upregulation of neuronal markers and downregulation of the astrocyte marker GFAP. The graph plots the expression of genes in the +gel set after normalization by the marker expression in the - gel control set. ( ${ }^{*} P<0.05$ indicates significance).

differentiation from neural precursor cells. ${ }^{35}$ Based on this observation, we examined the ability of the A5 hydrogel to promote the neuronal differentiation of MSCs. Bone marrow-derived hMSCs were seeded onto the A5 hydrogel and incubated. The control cells were seeded on glass coverslips. Starting on day 1, cells incubated on the gels showed a different morphology and less spreading compared with the glass control (Figure 4a). Interestingly, cells cultured on the gel showed a distinct neuron-like morphology (Figure 4a). A similar observation was also obtained for hydrogel A6 (Supplementary Figure S11).

The mean cell spread area on the A5 hydrogel on day 1 was $2700 \pm 960 \mu \mathrm{m}^{2}$, whereas it was $6000 \pm 4000 \mu \mathrm{m}^{2}$ for the control cells. On day 5 , the mean cell spread areas on the glass (control) and gels were $5800 \pm 2000$ and $4400 \pm 2100 \mu \mathrm{m}^{2}$, respectively. The mean cell spread area and circularity of the stem cells on the A5 hydrogel were less than those of the control at both time points (days 1 and 5). However, the variation was not significant between cultures on days 1 and 5 (Figure $4 \mathrm{~b}$ ). The cell spread area analysis showed elongated bipolar morphology on the A5 hydrogel from the early stages of culture, which elongated and branched further with time (Supplementary Figure S12). To further confirm the differentiation lineage of the hMSCs, the expression of genes associated with the neuronal differentiation of hMSCs cultured for 5 days on hydrogel A5 without growth factors was assessed using glass as a control (Figure 4c). The relatively high expression levels of ENO and TUBB3 (neural markers) and low levels of GFAP (astrocyte marker) indicated that the A5 gel promoted hMSC differentiation toward the neuronal lineage (Supplementary Table S1).

\section{Implantation of the gel and its inflammatory response in vivo} Implantable biomaterials that assist cell replacement therapies in the brain must be stable to support adequate cell engraftment. A major obstacle in the design of implantable materials in vivo is the inflammatory response of the materials after implantation. To assess the inflammatory response in vivo, the A5 hydrogel was implanted into the caudate putamen region of the adult rat brain, and astrogliosis was studied 7 and 21 days postimplantation (dpi). The hydrogel implant attracted both astrocytes and microglial cells 7 dpi (Figures $5 \mathrm{a}$ and b). A large number of activated microglia and astrocytes accumulated close to the hydrogel, and their number decreased as a function of the distance from the hydrogel. This distribution was anticipated owing to the introduction of a foreign material to the brain and the associated trauma of implantation. The recruited astrocytes were mainly confined to the material-tissue interface, whereas the microglial cells infiltrated into the hydrogel. At $21 \mathrm{dpi}$, the acute inflammatory reaction had subsided, as evidenced by the numbers of astrocytes (Figure 5c) and microglia (Figure 5d), which had drastically decreased and were similar to those of the sham control. Much of the hydrogel was also degraded at this time point, as evidenced by the Thioflavin S-stained brain sections (Supplementary Figure S13). We quantified the astrocyte (Figure 5e) and microglial response (Figure 5f) in the field under study (approximately $500 \mu \mathrm{m}$ from the center of implant) based on the total fluorescent intensity of GFAP and Iba1, respectively. At $7 \mathrm{dpi}$, the astrocyte response was higher for the hydrogel than the sham control. The astrocyte recruitment attenuated by 21 days, and the number of GFAP-positive cells decreased compared with the sham control set. An identical trend was also observed for the microglia, with cell numbers subsiding to physiological levels by 21 days.

\section{Stem cell transplantation in a Parkinsonian mouse model}

The efficacy of amyloid hydrogels as a transplantation vehicle for stem cells in the brain was assessed by first testing cell viability in $3 \mathrm{D}$-culture conditions. To construct a $3 \mathrm{D}$ cell culture system, the 

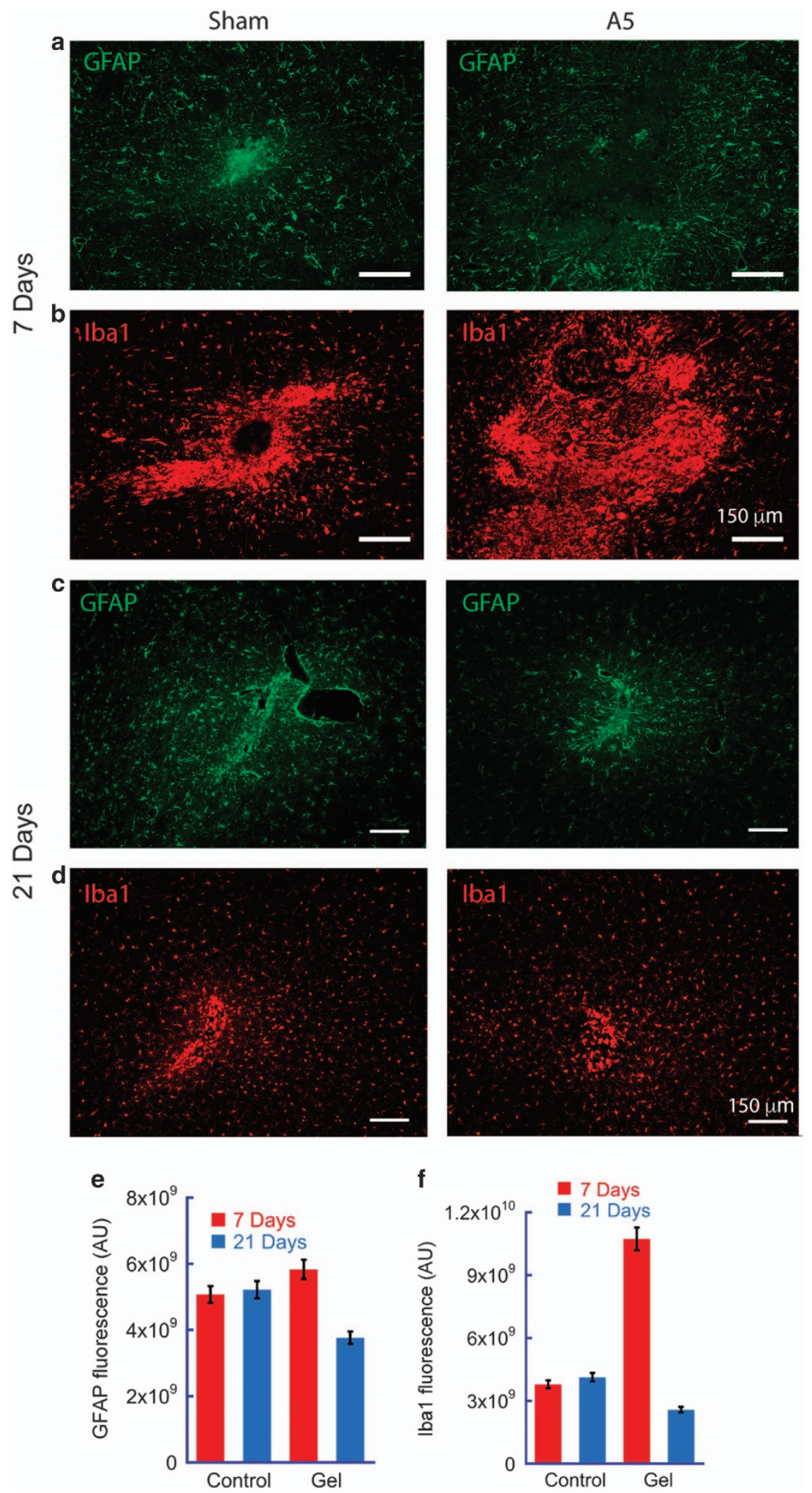

Figure 5 Inflammatory response 7 and 21 days after implantation. Astrocytes immunostained with anti-GFAP antibodies for the implanted hydrogel A5 (right panel) and sham control (left panel) at $7 \mathrm{dpi}$ (a) and $21 \mathrm{dpi}$ (c). Immunostaining was carried out with 20 - $\mu \mathrm{m}$-thick rat brain sections containing hydrogel implants. The contralateral hemispheres were used as a sham control. Microglial cells immunostained with anti-Ibal antibodies for the implanted hydrogel A5 (right panel) and sham control (left panel) at $7 \mathrm{dpi}$ (b) and $21 \mathrm{dpi}$ (d). Fewer activated cells are clearly evident in sections containing the A5 compared with the sham control. Quantification of the astrocyte (e) and microglia (f) population in and around the transplant bed in immunostained brain sections at 7 and $21 \mathrm{dpi}$. The plot represents the total fluorescence intensity of GFAP- and Iba1-stained slides after background correction. The scale bars represent $150 \mu \mathrm{m}$. 
self-healing behavior of the hydrogel was exploited. The A5 gel was briefly vortexed, the resulting solution was promptly mixed with SH-SY5Y cells and the system was allowed to form a gel for $15 \mathrm{~min}$.
Calcein-AM staining of SH-SY5Y cells embedded in the hydrogel after $24 \mathrm{~h}$ of incubation showed high viability within the hydrogel (Figure 6a). The same culturing technique was also used with
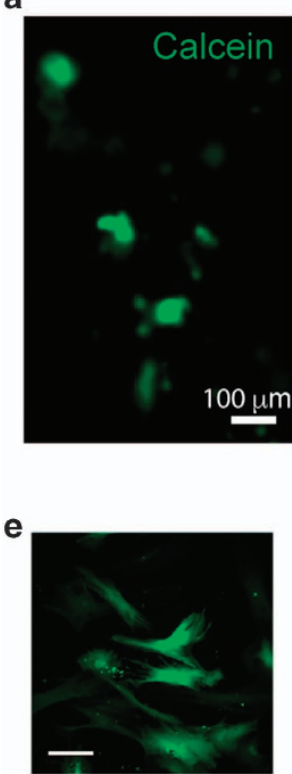

Stage 1

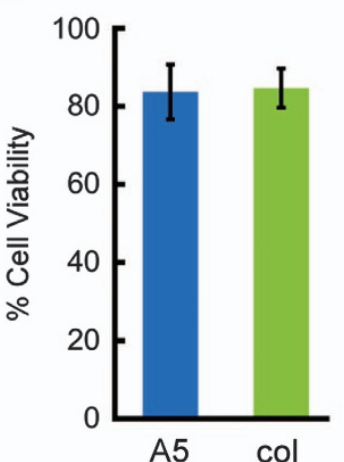

C

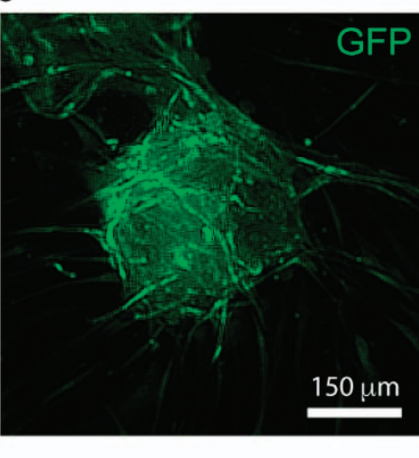

d

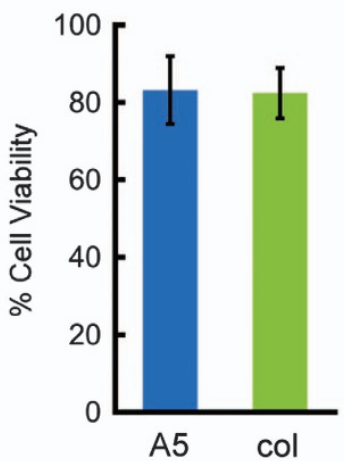

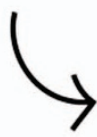

cells mixed with scaffold
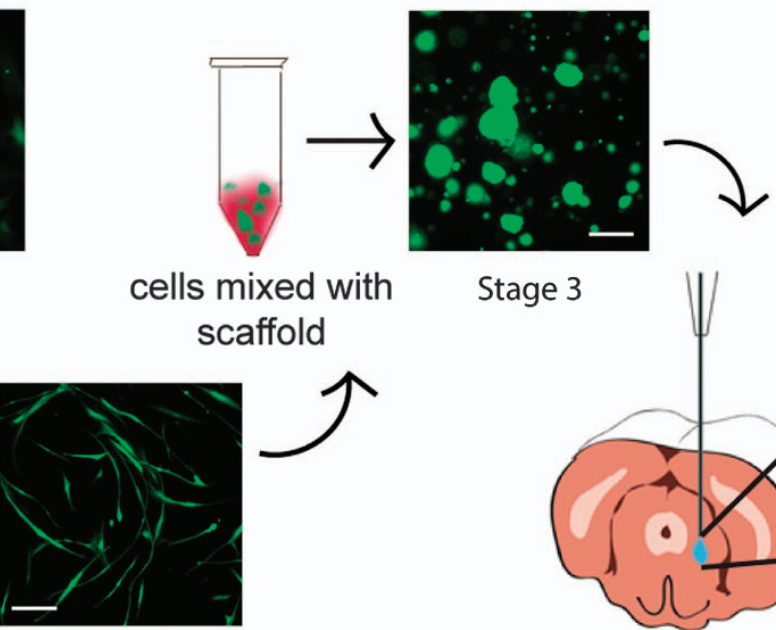

Stage 3
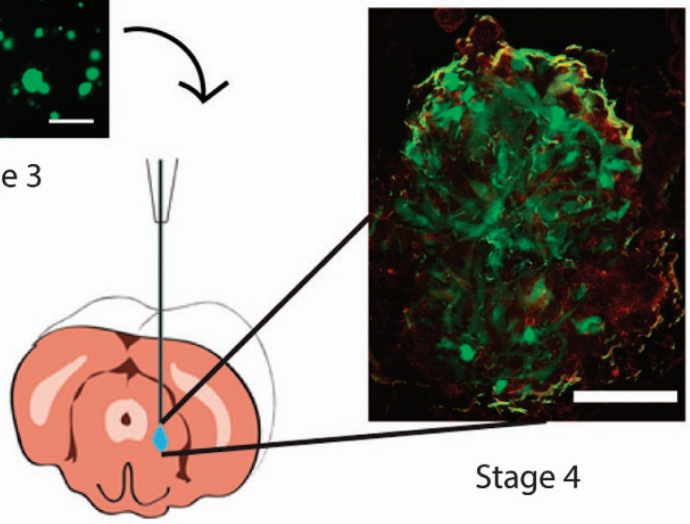

Stage 2

f
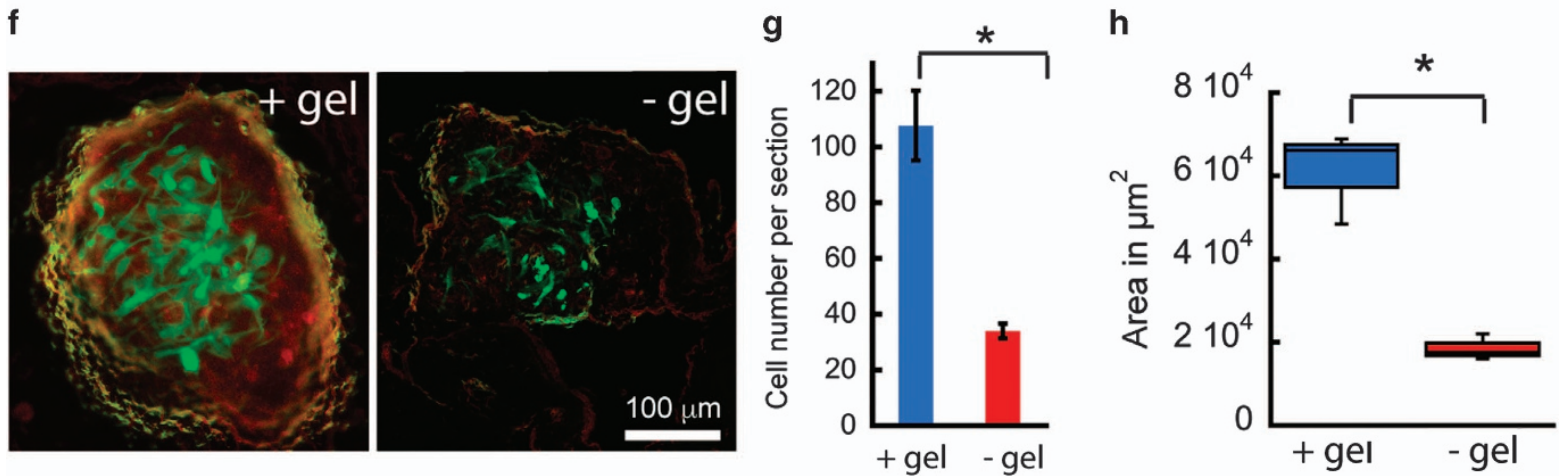

Figure 6 Implantation of primed hMSC into MPTP mouse brains. (a) Calcein-AM staining of SH-SY5Y cells cultured in 3D with hydrogel A5 showing viable cells inside the hydrogel. (b) Viability of 3D-cultured SH-SY5Y cells in A5 and collagen hydrogels quantified via an ATP luminescence assay (c) 3D culture showing GFP-hMSCs inside hydrogel A5. The scale bar represents $150 \mu \mathrm{m}$. (d) Viability of 3D-cultured hMSCs in A5 and collagen hydrogels quantified via an ATP luminescence assay. (e) Schematic of the morphology data of cells at each stage during the implantation study showing the transplantation of primed hMSCs. The cells were first plated and cultured in proliferation medium for $24 \mathrm{~h}$ (Stage 1). Subsequently, the cells were primed with differentiation medium for 5 days (Stage 2) and then transplanted with hydrogel A5 into the SNpc of MPTP mice (Stage 3). At 7 dpi in vivo, the brains were harvested and sectioned appropriately to reveal the graft (Stage 4). The scale bars represent $200 \mu \mathrm{m}$ for stages 1-3 and $100 \mu \mathrm{m}$ for Stage 4. (f) Implanted GFP-hMSCs with hydrogel A5 (left) at the caudate putamen after 7 days in vivo. Cells showing neuron-like morphology compared with cells implanted without hydrogel A5 (right). The implanted stem cells are shown in green, and the hydrogel is shown in red. The hydrogel was not stained with dye. The scale bar represents $100 \mu \mathrm{m}$. (g) The number of surviving cells per section at $7 \mathrm{dpi}$ when implanted with and without hydrogel A5. (h) Box plot of the area occupied by the surviving cells when transplanted with and without hydrogel A5. More cells survived when transplanted with the hydrogel. The number of transplanted cells and the area of the transplant bed were quantified with the ImageJ software. ( ${ }^{*}<0.05$ indicates significance). 

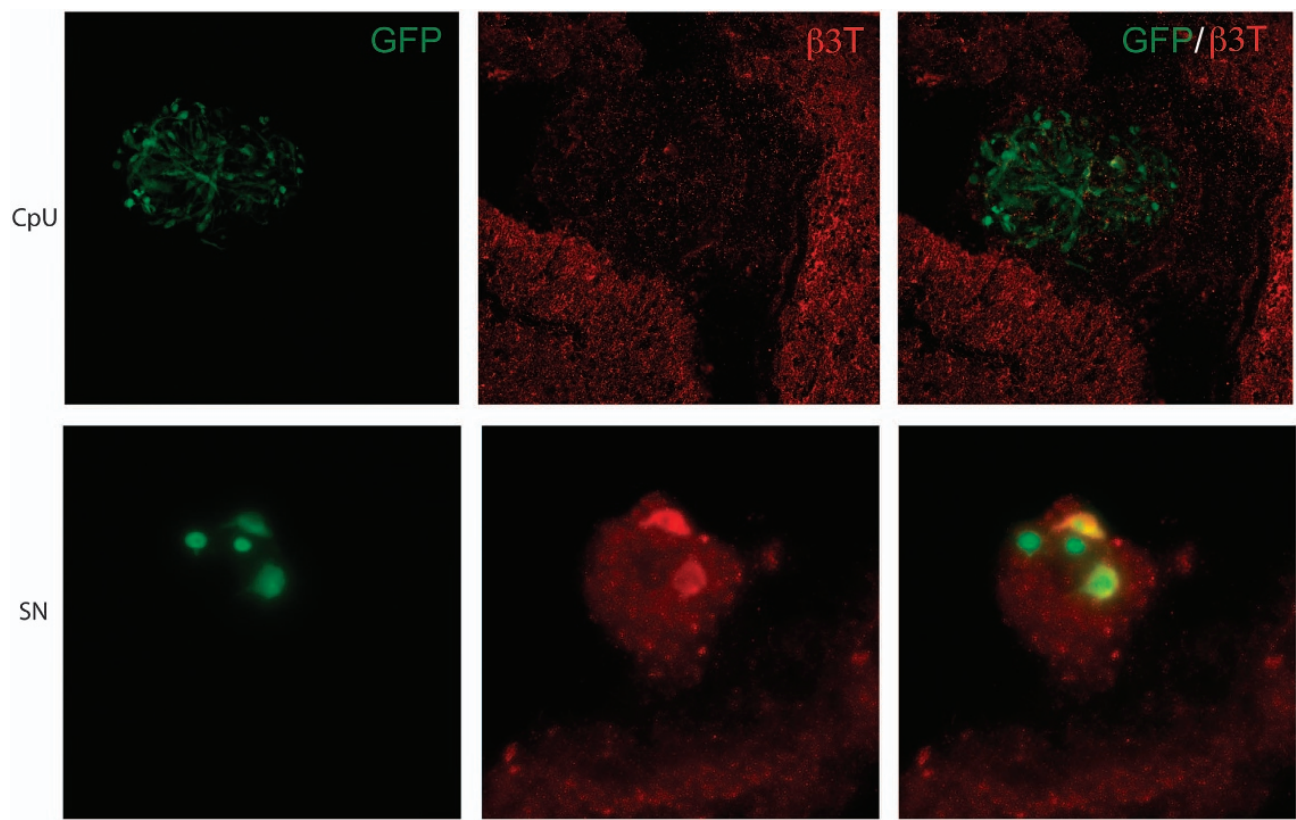
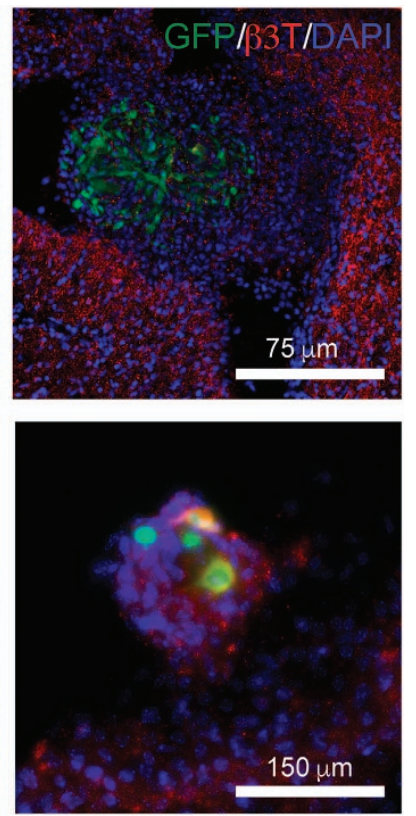

Figure 7 Immunostaining of neuronal markers of transplanted cell. $\beta$-III-Tubulin staining of transplanted cells in the caudate putamen (CPu) and substantia nigra (SN). The green channel represents the GFP signal from transplanted cells, the red channel represents the neuronal marker $\beta$-III-tubulin and the blue represents the nuclear stain DAPI. Cells transplanted into the SN stained positive for $\beta$-III-tubulin expression, indicating the neuronal lineage of differentiation. The scale bars represent $75 \mu \mathrm{m}$ (top) and $150 \mu \mathrm{m}$ (bottom).

GFP-hMSCs. The embedded cells were healthy and could be easily visualized in hydrogel A5 (Figure $6 \mathrm{c}$ ). The cell viability in the $3 \mathrm{D}$ environment of hydrogel A5 was quantified using an ATP-based luminescence assay (Figures $6 \mathrm{~b}$ and $\mathrm{d}$ ). Both SH-SY5Y cells and hMSCs were highly viable in $3 \mathrm{D}$ culture after $120 \mathrm{~h}$. For comparison purposes, an identical number of cells was cultured in a $3 \mathrm{D}$ collagen hydrogel. SH-SY5Y cells showed $84 \pm 7 \%$ viability in hydrogel A5 and $85 \pm 5 \%$ viability in collagen hydrogel. Similarly, hMSCs showed $83 \pm 8 \%$ and $82 \pm 6 \%$ viability in the A5 and collagen 1 hydrogels, respectively. Given the thixotropic nature of these hydrogels, cells could be easily loaded and delivered to the desired site via a minimally invasive injection. The transplantation was performed in MPTP mice, which are a standard Parkinsonian rodent model. The implantation was carried out at two different areas of the brain, the $\mathrm{SN}$ and striatum. Prior to implantation, GFP-hMSCs were treated for 5 days with a growth factor cocktail of $250 \mathrm{ng} \mathrm{ml}^{-1} \mathrm{SHH}, 100 \mathrm{ng} \mathrm{ml}^{-1}$ FGF-8 and $50 \mathrm{ng} \mathrm{ml}^{-1}$ FGF-2 in neurobasal media supplemented with $0.25 \%$ B27 (Figure 6e). This growth factor cocktail is reported to specifically drive hMSCs to DA neurons. ${ }^{36,37}$ A $23 \mathrm{G}$ needle with a suitable plunger fitted to a stereotactic frame was used to deliver the payload of GFP-hMSCs mixed with amyloid hydrogel A5. After transplantation, the system was left undisturbed for $5 \mathrm{~min}$, which assisted the gelation of the matrix. The cells were transplanted 3 weeks after MPTP was administered to the mice. As a control, equal numbers of cells in PBS were injected without the hydrogel. Immunosuppressants were not administered after the transplantation surgery. After 7 days (28 days post-MPTP injection), the mice were killed, and the transplant beds from the coronal sections of the harvested brain were assessed (Figure $6 \mathrm{f}$ and Supplementary Figure S14A). Hydrogel A5 was able to contain the cells at the transplantation site and enhance their survival, as evidenced by the larger number of GFP-positive cells. In the caudate putamen, the number of cells per section was $108 \pm 12$ with the gel and $34 \pm 2$ without the gel (Figure $6 \mathrm{~g}$ ). In the $\mathrm{SN}$, the cell number per section was $82 \pm 4$ with the gel and $20 \pm 3$ without the gel (Supplementary Figure S14B). The area occupied by the cells at the transplant bed also significantly differed between cells co-injected with the hydrogel and the cell-only control (Figure 6h and Supplementary Figure S14C). We also immunostained the brain sections for neuronal cell markers to determine the fate of the implanted cells. The cells transplanted in the SN along with hydrogel A5 stained positive for the neuronal marker $\beta$-III tubulin (Figure 7). The cells implanted without hydrogel A5 did not stain for $\beta$-III tubulin (Supplementary Figure S15). The data suggest that hydrogel A5 not only contained the cells and improved their survival in vivo but also promoted stem cells to differentiate toward a neuronal lineage in the SN.

\section{DISCUSSION}

Recent investigations suggest that $\alpha$-Syn amyloid fibrils, the end product of the aggregation pathway, are less toxic than soluble oligomers (intermediate product) both in vitro ${ }^{38}$ and in vivo. ${ }^{39}$ Furthermore, in a lentivirus PD rat model, the $\alpha$-Syn core segment (30-110 residues) was found to be less toxic than the full-length protein. ${ }^{39}$ Recently, we were also able to design non-toxic hydrogels from the $\mathrm{A} \beta \mathrm{C}$-terminus. ${ }^{17,40}$ Based on this finding, we hypothesized that non-toxic amyloid-based hydrogels could be designed from the $\alpha$-Syn core segment. We herein reported a new class of amyloidinspired peptide hydrogels based on the amyloidogenic segment of $\alpha$-Syn protein (Figure $1 b$ ). In this study, hydrogel formation from $\alpha$-Syn-derived peptides was triggered by various stimuli, such as heating/cooling or changes in $\mathrm{pH}$. Differential stimuli responsiveness was achieved by altering the side chain of the component peptides from the core sequence. This change altered the hydrophobicity or stacking interaction among the constituent peptides, making them aggregate and subsequently form supramolecular hydrogels under different conditions. The component peptides resemble cross- $\beta$-sheet- 
rich amyloids and assemble into a nanofibrous meshwork that mimics the natural extracellular matrix under physiological conditions (Figure $2 \mathrm{~d}$ ). The advantage of developing such peptide-based hydrogelators over commercially available protein-based gel systems is that their stiffness and side chains can be easily tuned for brain tissue engineering applications. Varying the salt component or concentration within physiological limits helps to modulate the storage modulus of the gels. Moreover, the components are well defined and can be easily and inexpensively synthesized. Extracellular matrix proteins, such as laminin and fibronectin, support neurite outgrowth in vitro because they contain special motifs that support neural cell adhesion and extension. ${ }^{41,42}$ These adhesion domains, when conjugated with other polymers, have been used as coating materials to culture neurons in a dish. ${ }^{15}$ Our self-healing hydrogel supports cell adhesion, survival, differentiation and neurite extension in vitro without the need for separate adhesion motifs (Figures $3 \mathrm{f}$ and $4 \mathrm{a}$ ). This property may be attributable to the nanotopography of the amyloid fibrils in the hydrogels. ${ }^{43}$ Furthermore, 'sticky' amyloid fibrils can easily sequester serum proteins from media, which may also additionally support neurite extension in vitro. ${ }^{43}$ Moreover, this hydrogel system could be easily translated to in vivo conditions owing to its thixotropic nature and its minimally invasive delivery to the target site. Concerns associated with the use of amyloid-inspired materials are relevant because many amyloids exhibit pathogenic and toxic properties. However, our engineered fibrils did not exhibit cytotoxicity in the MTT and luminescence viability assays nor were they able to act as seeds (for gel fibrils and degraded gel fragments) for inducing the aggregation of native $\alpha$-Syn, suggesting that these hydrogels are likely free of unwanted pathogenicity after implantation (Figures $3 a$ and $b$ ). These hydrogels also promote the neuronal differentiation of hMSCs in vitro. Stem cells are sensitive to various physical and biochemical cues at different stages of their development. ${ }^{44}$ These cues are provided by the extracellular matrix of the native niche in which the stem cell resides. ${ }^{45}$ Among these cues, matrix stiffness is a critical parameter that governs the fate of stem cell differentiation. ${ }^{35}$ To assess differentiation, cell circularity and the cell spreading area provides a good estimate of the morphology of cells. hMSCs cultured on hydrogels did not show a significant change in circularity but increased their spreading area by day 5 compared with day 1 (Figure 4b). This finding suggests that the cells were more polarized than control cells cultured on glass starting on day 1. Over time, cells grew in the direction of their major axis (if we consider the cell fitted to an ellipse, the growth was observed along the major axis). The elongation of the cells thereafter was reflected in the increase in cell area but not a significant change in circularity. This 'mechanistic' factor altered the cytoskeletal arrangement of the stem cells, as evidenced by the F-actin staining (Supplementary Figure S10) of hMSCs on glass and A5 hydrogel, and may have promoted differential gene expression. Our amyloid-based hydrogel system promotes the commitment of stem cells toward neurons, and this effect may be mediated by mechanotransduction. ${ }^{46-48}$ Hence, this type of hydrogel can promote neuronal differentiation without the need for any additional growth factors.

Acute inflammation followed by immune rejection is often associated with many scaffolds implanted in the brain, making them unsuitable for in vivo applications. When hydrogel A5 was implanted into the caudate putamen region of adult male Wistar rats, a relatively high astroglial response was observed at day 7, but this response eventually subsided below that of the sham control (PBS) by day 21 (Figures $5 \mathrm{e}$ and $\mathrm{f}$ ). Microglia were previously reported to actively participate in foreign body reactions of the central nervous system by sensing the environment of the brain and phagocytizing foreign materials. ${ }^{49}$ Specifically, microglia respond to a foreign body in two distinct phases. In the first phase, the microglia actively phagocytose the damaged tissue and foreign material. The microglia peak response during acute inflammation is reported to occur within 7 days of implantation. ${ }^{49}$ Earlier studies of hydrogels injected into the brain, such as chitosan, showed a prominent foreign body response which resulted in the entire material being phagocytosed within 7 days. ${ }^{50}$ In the second phase, microglia provide cytotrophic support by releasing anti-inflammatory cytokines that promote axon regeneration. ${ }^{51}$ Therefore, we selected 7 days as our first time point to evaluate the existence of the hydrogel after acute inflammation.

Although stem cell transplantation holds great promise in neural tissue engineering, ${ }^{52}$ the robustness of the engrafted transplanted cells in the existing central nervous system remains a serious limitation. Specifically, the low survival of the transplanted cells and their ectopic migration limit the success of stem cell-based therapies. ${ }^{53,54}$ Injectable hydrogel matrices can provide additional physical strength and enhance the survival ${ }^{55}$ of neural progenitor cells within a stroke cavity. ${ }^{56}$ Therefore, we used one of the optimized A5 amyloid hydrogels to transplant primed stem cells in a PD mouse model. The present amyloid-based hydrogels promote the differentiation of hMSCs to neuronal precursors but might not support their differentiation into specific neuronal lineages. Therefore, we hypothesized that priming the cells with growth factors may assist the stem cells to differentiate into functional DA neurons in vivo. Because we used a Parkinsonian mouse model for the in vivo study, DA-specific neuron regeneration would be beneficial. Specifically, the gel could induce differentiation to a neuronal lineage, and the growth factors could help to direct differentiation toward DA neurons. Therefore, we used primed hMSCs for transplantation in vivo. However, the tyrosine hydroxylase (DA neuron-specific marker) staining of the implanted cells in the brain sections was inconclusive, possibly owing to the background staining of the hydrogel (Supplementary Figure S16). In addition, the transplanted cells may still be immature where tyrosine hydroxylase is yet to be expressed, which is consistent with a previous study suggesting that growth factors allow hMSC differentiation to immature neuronal-like cells in immunosuppressed hemiparkinsonian rats. ${ }^{36}$ However, the data show a threefold increase in the area and number of viable cells transplanted with the hydrogel compared with cells transplanted alone (Figures $6 \mathrm{~g}$ and $\mathrm{h}$ ) in non-immunosuppressed MPTP mice. The transplanted cells also stained for the neuronal marker $\beta$-III tubulin in the SN when implanted with the hydrogel but not when implanted alone (Figure 7 and Supplementary Figure S15). Because primed hMSCs were used for the current study, delineating the relative contributions of the growth factor-based priming process and the mechanical signals from the hydrogel to the neural differentiation in vivo at this stage is difficult. Further implantation studies using unprimed cells and longer time points are required to affirm the contribution of amyloid hydrogels to neuronal differentiation in vivo. Nevertheless, the amyloid hydrogel clearly provided transplanted cells with a microenvironment conducive to cell survival in the diseased brain. To our knowledge, this study is the first to use amyloid hydrogels for the transplantation of stem cells into the brain.

In conclusion, we have developed a smart hydrogel system based on amyloids that is non-toxic, does not evoke an excessive immune response and supports in vitro neuronal differentiation, possibly via mechanical stimulation. This system could serve as a biomaterial for stem cell differentiation both in vitro and in vivo as well as a vehicle for stem cell-based therapeutics in tissue engineering. 


\section{CONFLICT OF INTEREST}

The authors declare no conflict of interest.

\section{ACKNOWLEDGEMENTS}

We thank the IITB-Monash Research Academy for their financial support, the Central SPM Facility (IRCC, IIT Bombay) for the AFM imaging, SAIF (IIT Bombay) for the FTIR spectroscopy and Amelia Sedjahtera of the Florey Institute of Neuroscience and Mental Health for her help in the preparation of MPTP mice. SKM acknowledges DBT (BT/PR9797/NNT/28/774/2014) from the Government of India. CCB is supported by grants from the National Health and Medical Research Council of Australia (APP1053621) and the Department of Industry of the Commonwealth of Australia (AISRF06680). We also thank Dr John Haynes of the Monash Institute of Pharmaceutical Science (MIPS) for his valuable suggestions on stem cell priming prior transplantation. SD thanks Srivastav Ranganathan, Saroj Rout for helping with the schematics and Dr Shimul Salot for critically reading the manuscript. SD also thanks SERB, CII and Piramal Enterprises for the Prime Minister's doctoral fellowship.

Author contributions: SD, SKM, JSF and DIF designed the research; SD, KZ, DG, NJ, PKS and RSJ performed experiments; CCB provided key reagents and analytical tools; SD, DG, KZ, CCB, DIF, JSF and SKM analyzed the data; SD, JSF and SKM wrote the paper.

1 Chiti, F. \& Dobson, C. M. Protein misfolding, functional amyloid, and human disease. Annu. Rev. Biochem. 75, 333-366 (2006)

2 Chapman, M. R., Robinson, L. S., Pinkner, J. S., Roth, R., Heuser, J., Hammar, M. Normark, S. \& Hultgren, S. J. Role of Escherichia coli curli operons in directing amyloid fiber formation. Science 295, 851-855 (2002).

3 Maji, S. K., Perrin, M. H., Sawaya, M. R., Jessberger, S., Vadodaria, K., Rissman, R. A., Singru, P. S., Nilsson, K. P., Simon, R., Schubert, D., Eisenberg, D., Rivier, J., Sawchenko, P., Vale, W. \& Riek, R. Functional amyloids as natural storage of peptide hormones in pituitary secretory granules. Science 325, 328-332 (2009).

4 Cherny, I. \& Gazit, E. Amyloids: not only pathological agents but also ordered nanomaterials. Angew. Chem. Int. Ed. 47, 4062-4069 (2008).

5 Hamada, D., Yanagihara, I. \& Tsumoto, K. Engineering amyloidogenicity towards the development of nanofibrillar materials. Trends Biotechnol. 22, 93-97 (2004)

6 Reynolds, N. P., Styan, K. E., Easton, C. D., Li, Y., Waddington, L., Lara, C., Forsythe, J. S., Mezzenga, R., Hartley, P. G. \& Muir, B. W. Nanotopographic surfaces with defined surface chemistries from amyloid fibril networks can control cell attachment. Biomacromolecules 14, 2305-2316 (2013).

7 Bongiovanni, M. N., Scanlon, D. B. \& Gras, S. L. Functional fibrils derived from the peptide TTR1-cycloRGDfK that target cell adhesion and spreading. Biomaterials $\mathbf{3 2}$, 6099-6110 (2011).

8 Mankar, S., Anoop, A., Sen, S. \& Maji, S. K. Nanomaterials: amyloids reflect their brighter side. Nano Rev. (e-pub ahead of print 31 May 2011; doi:10.3402/nani. v2i0.6032).

9 Nelson, R. \& Eisenberg, D. Recent atomic models of amyloid fibril structure. Curr. Opin. Struct. Biol. 16, 260-265 (2006).

10 Calamai, M., Kumita, J. R., Mifsud, J., Parrini, C., Ramazzotti, M., Ramponi, G., Taddei, N., Chiti, F. \& Dobson, C. M. Nature and significance of the interactions between amyloid fibrils and biological polyelectrolytes. Biochemistry 45, 12806-12815 (2006).

11 Maji, S. K., Wang, L., Greenwald, J. \& Riek, R. Structure-activity relationship of amyloid fibrils. FEBS Lett. 583, 2610-2617 (2009).

12 Lindvall, O. \& Kokaia, Z. Stem cells for the treatment of neurological disorders. Nature 441, 1094-1096 (2006)

13 Mahoney, M. J. \& Anseth, K. S. Three-dimensional growth and function of neural tissue in degradable polyethylene glycol hydrogels. Biomaterials 27, 2265-2274 (2005).

14 Cooke, M. J., Vulic, K. \& Shoichet, M. S. Design of biomaterials to enhance stem cell survival when transplanted into the damaged central nervous system. Soft Matter 6 4988-4998 (2010).

15 Tam, R. Y., Fuehrmann, T., Mitrousis, N. \& Shoichet, M. S. Regenerative therapies for central nervous system diseases: a biomaterials approach. Neuropsychopharmacology 39, 169-188 (2014).

16 Reynolds, N. P., Charnley, M., Mezzenga, R. \& Hartley, P. G. Engineered lysozyme amyloid fibril networks support cellular growth and spreading. Biomacromolecules 15, 599-608 (2014).

17 Jacob, R. S., Ghosh, D., Singh, P. K., Basu, S. K., Jha, N. N., Das, S. Sukul, P. K., Patil, S., Sathaye, S., Kumar, A., Chowdhury, A., Malik, S., Sen, S. \& Maji, S. K. Self healing hydrogels composed of amyloid nano fibrils for cell culture and stem cell differentiation. Biomaterials 54, 97-105 (2015).

18 Gras, S. L., Tickler, A. K., Squires, A. M., Devlin, G. L., Horton, M. A., Dobson, C. M. \& MacPhee, C. E. Functionalised amyloid fibrils for roles in cell adhesion. Biomaterials 29, 1553-1562 (2008).
19 Li, C., Born, A. K., Schweizer, T., Zenobi-Wong, M., Cerruti, M. \& Mezzenga, R. Amyloid-hydroxyapatite bone biomimetic composites. Adv. Mater. 26, 3207-3212 (2014).

20 Volles, M. J. \& Lansbury, P. T. Relationships between the sequence of $\alpha$-synuclein and its membrane affinity, fibrillization propensity, and yeast toxicity. J. Mol. Biol. 366, 1510-1522 (2007).

21 Ghosh, D. \& Maji, S. K. Preparation of aggregate-free $\alpha$-synuclein for in vitro aggregation study. Protoc. Exchange, doi:10.1038/protex.2015.037 (2015).

22 Giehm, L. \& Otzen, D. E. Strategies to increase the reproducibility of protein fibrillization in plate reader assays. Anal. Biochem. 400, 270-281 (2010).

23 Bousset, L., Pieri, L., Ruiz-Arlandis, G., Gath, J., Jensen, P. H., Habenstein, B., Madiona, K., Olieric, V., Böckmann, A., Meier, B. H. \& Melki, R. Structural and functional characterization of two alpha-synuclein strains. Nat. Commun. 4, 2575 (2013).

24 Singh, P. K., Kotia, V., Ghosh, D., Mohite, G. M., Kumar, A. \& Maji, S. K. Curcumin modulates $\alpha$-synuclein aggregation and toxicity. ACS Chem. Neurosci. 4, 393-407 (2012).

25 Smith, A. M., Williams, R. J., Tang, C., Coppo, P., Collins, R. F., Turner, M. L., Saiani, A. \& Ulijn, R. V. Fmoc-diphenylalanine self assembles to a hydrogel via a novel architecture based on $\pi-\pi$ interlocked $\beta$-sheets. Adv. Mater. 20, 37-41 (2008).

26 LeVine, H. 3rd Quantification of beta-sheet amyloid fibril structures with thioflavin T. Methods Enzymol. 309, 274-284 (1999).

27 Sunde, M. \& Blake, C. The structure of amyloid fibrils by electron microscopy and X-ray diffraction. Adv. Protein. Chem. 50, 123-159 (1997).

28 Jackson, M. \& Mantsch, H. H. The use and misuse of FTIR spectroscopy in the determination of protein structure. Crit. Rev. Biochem. Mol. Biol. 30, 95-120 (1995).

29 Selkoe, D. J. Folding proteins in fatal ways. Nature 426, 900-904 (2003).

30 Mosmann, T. Rapid colorimetric assay for cellular growth and survival: application to proliferation and cytotoxicity assays. J. Immunol. Methods 65, 55-63 (1983).

31 Wood, S. J., Wypych, J., Steavenson, S., Louis, J.-C., Citron, M. \& Biere, A. L. $\alpha$-Synuclein fibrillogenesis is nucleation-dependent: implications for the pathogenesis of Parkinson's disease. J. Biol. Chem. 274, 19509-19512 (1999).

32 Conway, K. A., Harper, J. D. \& Lansbury, P. T. Accelerated in vitro fibril formation by mutant $\alpha$-synuclein linked to early-onset Parkinson disease. Nat. Med. 4, 1318-1320 (1998).

33 Breydo, L., Wu, J. W. \& Uversky, V. N. $\alpha$-Synuclein misfolding and Parkinson's disease. Biochim. Biophys. Acta 1822, 261-285 (2012).

34 Willander, H., Presto, J., Askarieh, G., Biverstål, H., Frohm, B., Knight, S. D., Johansson, J. \& Linse, S. BRICHOS domains efficiently delay fibrillation of amyloid B-peptide. J. Biol. Chem. 287, 31608-31617 (2012).

35 Engler, A. J., Sen, S., Sweeney, H. L. \& Discher, D. E. Matrix elasticity directs stem cell lineage specification. Cell 126, 677-689 (2006).

36 Khoo, M. L. M., Tao, H., Meedeniya, A. C. B., Mackay-Sim, A. \& Ma, D. D. F. Transplantation of neuronal-primed human bone marrow mesenchymal stem cells in hemiparkinsonian rodents. PLoS One 6, e19025 (2011)

37 Trzaska, K. A., Kuzhikandathil, E. V. \& Rameshwar, P. Specification of a dopaminergic phenotype from adult human mesenchymal stem cells. Stem Cells 25, 2797-2808 (2007).

38 Danzer, K. M., Haasen, D., Karow, A. R., Moussaud, S., Habeck, M., Giese, A., Kretzschmar, H., Hengerer, B. \& Kostka, M. Different species of alpha-synuclein oligomers induce calcium influx and seeding. J. Neurosci. 27, 9220-9232 (2007).

39 Winner, B., Jappelli, R., Maji, S. K., Desplats, P. A., Boyer, L., Aigner, S., Hetzer, C., Loher, T., Vilar, M., Campioni, S., Tzitzilonis, C., Soragni, A., Jessberger, S., Mira, H., Consiglio, A., Pham, E., Masliah, E., Gage, F. H. \& Riek, R. In vivo demonstration that $\alpha$-synuclein oligomers are toxic. Proc. Natl. Acad. Sci. 108, 4194-4199 (2011).

40 Jacob, R. S., Das, S., Ghosh, D. \& Maji, S. K. Influence of retinoic acid on mesenchymal stem cell differentiation in amyloid hydrogels. Data Brief $\mathbf{5}$, 954-958 (2015).

41 Hersel, U., Dahmen, C. \& Kessler, H. RGD modified polymers: biomaterials for stimulated cell adhesion and beyond. Biomaterials 24, 4385-4415 (2003).

42 Tashiro, K., Sephel, G. C., Weeks, B., Sasaki, M., Martin, G. R., Kleinman, H. K. \& Yamada, Y. A synthetic peptide containing the IKVAV sequence from the A chain of laminin mediates cell attachment, migration, and neurite outgrowth. J. Biol. Chem. 264, 16174-16182 (1989).

43 Jacob, R. S., George, E., Singh, P. K., Salot, S., Anoop, A., Jha, N. N., Sen, S. \& Maji, S. K. Cell adhesion on amyloid fibrils lacking integrin recognition motif. J. Biol. Chem. 291, 5278-5298 (2016).

44 Discher, D. E., Mooney, D. J. \& Zandstra, P. W. Growth factors, matrices, and forces combine and control stem cells. Science 324, 1673-1677 (2009).

45 Reilly, G. C. \& Engler, A. J. Intrinsic extracellular matrix properties regulate stem cell differentiation. J. Biomech. 43, 55-62 (2010).

46 Teo, B. K., Wong, S. T., Lim, C. K., Kung, T. Y., Yap, C. H., Ramagopal, Y. Romer, L. H. \& Yim, E. K. Nanotopography modulates mechanotransduction of stem cells and induces differentiation through focal adhesion kinase. ACS Nano 7, 4785-4798 (2013).

47 Wang, Y.-K. \& Chen, C. S. Cell adhesion and mechanical stimulation in the regulation of mesenchymal stem cell differentiation. J. Cell. Mol. Med. 17, 823-832 (2013).

48 Wen, J. H., Vincent, L. G., Fuhrmann, A., Choi, Y. S., Hribar, K. C., Taylor-Weiner, H., Chen, S. \& Engler, A. J. Interplay of matrix stiffness and protein tethering in stem cell differentiation. Nat. Mater. 13, 979-987 (2014). 
49 Nisbet, D. R., Rodda, A. E., Horne, M. K., Forsythe, J. S. \& Finkelstein, D. I. Neurite infiltration and cellular response to electrospun polycaprolactone scaffolds implanted into the brain. Biomaterials 30, 4573-4580 (2009).

50 Crompton, K. E., Tomas, D., Finkelstein, D. I., Marr, M., Forsythe, J. S. \& Horne, M. K. Inflammatory response on injection of chitosan/GP to the brain. J. Mater. Sci. Mater. Med. 17, 633-639 (2006).

51 Ritter, M. R., Banin, E., Moreno, S. K., Aguilar, E., Dorrell, M. I. \& Friedlander, M. Myeloid progenitors differentiate into microglia and promote vascular repair in a model of ischemic retinopathy. J. Clin. Invest. 116, 3266-3276 (2006).

52 Malgosia, M. P., Brian, G. B. \& Molly, S. S. Injectable hydrogels for central nervous system therapy. Biomed. Mater. 7, 024101 (2012).

53 Walker, P. A., Shah, S. K., Harting, M. T. \& Cox, C. S. Progenitor cell therapies for traumatic brain injury: barriers and opportunities in translation. Dis. Model Mech. 2, 23-38 (2009).

54 Nakaji-Hirabayashi, T., Kato, K. \& Iwata, H. In vivo study on the survival of neural stem cells transplanted into the rat brain with a collagen hydrogel that incorporates lamininderived polypeptides. Bioconjug. Chem. 24, 1798-1804 (2013).

55 Giordano, C., Albani, D., Gloria, A., Tunesi, M., Batelli, S., Russo, T., Forloni, G., Ambrosio, L. \& Cigada, A. Multidisciplinary perspectives for Alzheimer's and Parkinson's diseases hydrogels for protein delivery and cell-based drug delivery as therapeutic strategies. Int. J. Artif. Organs 32, 836-850 (2009).
56 Zhong, J., Chan, A., Morad, L., Kornblum, H. I., Fan, G. \& Carmichael, S. T. Hydrogel matrix to support stem cell survival after brain transplantation in stroke. Neurorehabil. Neural Repair 24, 636-644 (2010).

57 Li, D., Jones, E. M., Sawaya, M. R.,. Furukawa, H., Luo, F., Ivanova, M., Sievers, S. A., Wang, W., Yaghi, O. M., Liu, C. \& Eisenberg, D. S. Structure-based design of functional amyloid materials. J. Am. Chem. Soc. 136, 18044-18051 (2014).

This work is licensed under a Creative Commons Attribution 4.0 International License. The images or other third party material in this article are included in the article's Creative Commons license, unless indicated otherwise in the credit line; if the material is not included under the Creative Commons license, users will need to obtain permission from the license holder to reproduce the material. To view a copy of this license, visit http:// creativecommons.org/licenses/by/4.0/

(C) The Author(s) 2016

Supplementary Information accompanies the paper on the NPG Asia Materials website (http://www.nature.com/am) 